\title{
Ocean carbon pump decomposition and its application to CMIP5 earth system model simulations
}

Akira Oka®

\begin{abstract}
The ocean stores 60 times as much carbon as the atmosphere, and the ocean carbon cycle has a critical role in controlling atmospheric $\mathrm{CO}_{2}$ concentration. The concept of ocean carbon pump is widely used for describing the ocean carbon cycle, but the term "ocean carbon pump" is not necessarily strictly defined and has been differently referred in previous studies. Here, using three dimensional distributions of dissolved inorganic carbon concentration, total alkalinity, phosphate, and salinity, four types of ocean carbon pump (organic matter, calcium carbonate, gas exchange, and freshwater flux pumps) were formulated. Although previously proposed decomposition emphasizes the enrichment in the deep ocean, my decomposition focuses on surface depletion which directly affects air-sea $\mathrm{CO}_{2}$ exchanges. Based on this decomposition, vector diagram for quantifying the individual roles of the pumps in controlling the ocean surface $\mathrm{pCO}_{2}$, which is in balance with atmospheric $\mathrm{CO}_{2}$ concentration, was demonstrated in this study. The method was applied to the observational climatology, and the contributions of the four carbon pump components to atmospheric $\mathrm{CO}_{2}$ were visualized in a single figure (the vector diagram); each carbon pump component was represented by one vector, and its contribution to $\mathrm{CO}_{2}$ concentration was measured from the difference in the contour values between the beginning and end of the vector. The same analysis was also applied to the CMIP5 earth system model simulations. All the models reproduced the same level of atmospheric $\mathrm{CO}_{2}$ concentration as the observation; however, the contributions from the four carbon pumps varied. The vector diagram was shown to quantify the differences in the contributions from the pumps between the models and against the observation. This study demonstrated that the proposed vector diagram analysis is a useful tool for quantifying the individual contributions of the ocean carbon pumps to atmospheric $\mathrm{CO}_{2}$ concentration and is helpful for evaluating the reproducibility of ocean carbon cycle models.
\end{abstract}

Keywords: Ocean carbon cycle, Atmospheric $\mathrm{CO}_{2}$ concentration, Ocean carbon pump, Vector diagram analysis, CMIP5 models

\section{Introduction}

The ocean contains about $38,000 \mathrm{Pg}$ of carbon, which is 60 times more than the atmosphere (Sarmiento and Gruber 2002; Solomon et al. 2007). The ocean carbon cycle plays a critical role in controlling atmospheric $\mathrm{CO}_{2}$ concentration. For example, the ocean carbon cycle is regarded as the most important factor in explaining

Correspondence: akira@aori.u-tokyo.ac.jp

Atmosphere and Ocean Research Institute, The University of Tokyo, 5-1-5 Kashiwanoha, Kashiwa, Chiba 277-8564, Japan glacial-interglacial $\mathrm{CO}_{2}$ variations of about $100 \mathrm{ppm}$ (Sigman and Boyle 2000; Sigman et al. 2010; Oka et al. 2011a; Kobayashi and Oka 2018; Yamamoto et al. 2019; Gottschalk et al. 2019). In the present-day ocean, surface concentrations of dissolved inorganic carbon (DIC) and total alkalinity (ALK) are lower than in the deep ocean, which maintains the present-day level of atmospheric $\mathrm{CO}_{2}$ concentration. The processes controlling such vertical gradients of DIC and ALK are often referred to as "ocean carbon pumps," and their investigation is one of
Springer Open (c) The Author(s). 2020 Open Access This article is licensed under a Creative Commons Attribution 4.0 International License, which permits use, sharing, adaptation, distribution and reproduction in any medium or format, as long as you give appropriate credit to the original author(s) and the source, provide a link to the Creative Commons licence, and indicate if changes were made. The images or other third party material in this article are included in the article's Creative Commons licence, unless indicated otherwise in a credit line to the material. If material is not included in the article's Creative Commons licence and your intended use is not permitted by statutory regulation or exceeds the permitted use, you will need to obtain permission directly from the copyright holder. To view a copy of this licence, visit http://creativecommons.org/licenses/by/4.0/. 
the most important aspects of ocean biogeochemistry (Broecker and Peng 1982; Sarmiento and Gruber 2006). To understand the mechanisms of the ocean carbon pumps, their decomposition into several parts has been proposed in previous studies/textbooks (Baes 1982; Volk and Hoffert 1985; Sarmiento and Gruber 2006). For example, focusing on the role of organic matter and calcium carbonate, the vertical gradients of DIC and ALK, associated with their production in the upper ocean and remineralization in the deeper ocean, are referred to as "organic matter" (or soft-tissue) and "calcium carbonate" (or hard-tissue) pumps, respectively (Yamanaka and Tajika 1996). In addition, the distributions of DIC and ALK are affected significantly by surface freshwater flux in the same way as salinity and their effects on the vertical gradients of DIC and ALK are not negligible. Surface gas exchange with the atmosphere also affects the vertical gradient of DIC. These two processes (i.e., freshwater flux and gas exchange) are expected to operate as parts of ocean carbon pumps, but they have not been necessarily treated explicitly within the framework of ocean carbon pumps. Although the decomposition of ocean carbon pumps into several parts is recognized as a useful approach (Ito and Follows 2005; Cameron et al. 2005; Yoshikawa et al. 2008; Marinov et al. 2008), a definition of ocean carbon pumps has not been necessarily common among the various studies, and thus, the detailed treatment of their decomposition has been specific to each study.

An appropriate method for diagnosing the ocean carbon pumps is also important for the evaluation of the ocean carbon cycle models that are used for predicting atmospheric $\mathrm{CO}_{2}$ concentration. In the IPCC report AR5 and Coupled Model Intercomparison Project phase 5 (CMIP5), various types of climate models are referenced. In the earth system model (ESM), biogeochemical cycles including the ocean carbon cycle are predicted explicitly (Solomon et al. 2007; Flato 2011; Taylor et al. 2012). Diagnosing the states of the ocean carbon pumps simulated in these models and comparing them with the observational data is an important step for evaluating the ability of the models to predict future changes in the ocean carbon cycle and their consequent effects on atmospheric $\mathrm{CO}_{2}$ concentration (Sarmiento et al. 1998; Yoshikawa et al. 2008; Zickfeld et al. 2008; Yamamoto et al. 2018). Decomposition of the ocean carbon pumps will be also helpful for understanding the role of ocean carbon cycle in atmospheric $\mathrm{CO}_{2}$ concentration in past climate such as glacial climate (Sigman et al. 2010; Kwon et al. 2012; Khatiwala et al. 2019).

In this paper, the decomposition of ocean carbon pumps is revisited and a simple and useful method for analyzing ocean carbon pumps is proposed. In the analysis, the variation of oceanic $\mathrm{pCO}_{2}$ is decomposed into contributions from four carbon pumps: the organic matter, calcium carbonate, air-sea gas exchange, and freshwater flux pumps. The results of this analysis can be summarized in a single figure (the vector diagram) where each carbon pump component is represented by one vector, and its contribution to $\mathrm{pCO}_{2}$ is referenced from the difference in the contour values between the beginning and end of the vector. This decomposition can be possible simply from three-dimensional distributions of phosphate, DIC, ALK, and salinity with an assumption of constant stochiometric ratios. The usefulness of the decomposition of carbon pumps has already been recognized in many previous studies (e.g., Sarmiento and Gruber 2006; Kwon et al. 2009); however, the way to decompose the ocean carbon pumps was not strictly common among the studies. Therefore, the objectives of this study were to provide both a clear definition of each carbon pump component and a useful framework for the evaluation of their individual effects on atmospheric $\mathrm{CO}_{2}$ concentration. The clear description on the carbon pump decompositions and discussion about its effect on atmospheric $\mathrm{CO}_{2}$ concentration will be useful not only for research purposes but also for educational purposes especially for students who begin to learn ocean biogeochemistry. By applying the abovementioned method to climatological state of observational data, it is shown that the present-day state of the four carbon pumps and their effects on atmospheric $\mathrm{CO}_{2}$ concentration can be clearly evaluated. The method was also applied to CMIP5 ESM simulations, and the reproducibility of the model was discussed based on a comparison of the results with the observation.

The remainder of the paper is organized as follows. In the "Methods" section, the method for the decomposition of ocean carbon pumps is explained. In the "Results and discussion" section, this decomposition is applied to the observational data and CMIP5 simulations. Based on this decomposition, the effects of each carbon pump on oceanic $\mathrm{pCO}_{2}$ are quantified using the vector diagram analysis. The conclusions are provided in the "Conclusions" section.

\section{Methods}

\section{Ocean carbon pump decomposition}

Each carbon pump is defined from its contribution to the vertical transport of carbon from the surface to the deep ocean which causes vertical gradient of carbon concentration in the ocean. In the previous studies, the enrichment of the carbon in the deep ocean compared with the surface is usually emphasized and the deviation of carbon concentration from the surface value is often used for the formulation. In this study, for assessing effects on atmospheric $\mathrm{CO}_{2}$ concentration more directly, the decomposition of ocean carbon pump is formulated by focusing on "surface depletion" of carbon concentration rather than its "deep 
enrichment." For this reason, the deviation of carbon concentration from the globally averaged value is used for the decomposition (note that some previous studies also applied the same approach; e.g., Kwon and Primeau 2008). The detail formulation of carbon pump decomposition will be described below.

The deviation of dissolved inorganic carbon concentration from the globally averaged value $(\triangle D I C)$ is decomposed into components associated with organic matter $\left(\Delta C_{\text {org }}\right)$, calcium carbonate $\left(\Delta C_{\text {caco3 }}\right)$, air-sea gas exchange $\left(\Delta C_{\text {gas }}\right)$, and freshwater flux $\left(\Delta C_{\mathrm{fw}}\right)$ :

$$
\Delta \mathrm{DIC}=\mathrm{DIC}-[\mathrm{DIC}]_{\mathrm{avr}}=\Delta C_{\mathrm{org}}+\Delta C_{\mathrm{caco} 3}+\Delta C_{\mathrm{gas}}+\Delta C_{\mathrm{fw}},
$$

where the global volume-averaged value is noted in parentheses with the suffix avr, and the deviation from the average is indicated by the prefix $\Delta$. By assuming constant stoichiometric ratios of organic matter and using the distributions of alkalinity (ALK), phosphate $(P)$, and salinity, this decomposition is here formulated as follows:

$$
\begin{aligned}
& \Delta C_{\mathrm{org}}=r_{\mathrm{CP}}\left(s P-[s P]_{\mathrm{avr}}\right), \\
& \Delta C_{\mathrm{caco} 3}=\frac{1}{2}\left(s \mathrm{ALK}-[s \mathrm{ALK}]_{\mathrm{avr}}+r_{\mathrm{NP}}\left(s P-[s P]_{\mathrm{avr}}\right)\right), \\
& \Delta C_{\mathrm{gas}}=s \mathrm{DIC}-[s \mathrm{DIC}]_{\mathrm{avr}}-\Delta C_{\mathrm{org}}-\Delta C_{\mathrm{caco} 3}, \\
& \Delta C_{\mathrm{fw}}=\left(\mathrm{DIC}-[\mathrm{DIC}]_{\mathrm{avr}}\right)-\left(s \mathrm{DIC}-[s \mathrm{DIC}]_{\mathrm{avr}}\right),
\end{aligned}
$$

where $r_{\mathrm{CP}}$ and $r_{\mathrm{NP}}$ are the stoichiometric ratios of carbon and nitrogen to phosphorous, respectively, and the prefix $s$ indicates the salinity-normalized value (e.g., $s \mathrm{DIC}=\frac{\mathrm{DIC}}{S} \times S_{\text {ref }}$, where $S$ is salinity and $S_{\text {ref }}$ is the reference salinity). The decomposition introduced here is basically the same as that of Sarmiento and Gruber (2006), except that each carbon pump component is defined in order to express the deviation from the globally averaged value, the gas exchange pump is defined more simply, and the freshwater flux pump is considered explicitly.

Here, we review the meaning of the abovementioned decomposition. The prognostic equation of $s \mathrm{DIC}$ can be written symbolically as

$$
\frac{\partial s \mathrm{DIC}}{\partial t}=T_{\mathrm{adv} v \text { diff }}(s \mathrm{DIC})+S_{\mathrm{org}}(s \mathrm{DIC})+S_{\mathrm{caco3}}(s \mathrm{DIC})+S_{\mathrm{gas}}(s \mathrm{DIC}),
$$

where $T_{\mathrm{adv}}+$ diff represents ocean transport by advection and diffusion, and the other terms on the righthand side are the source/sink terms of carbon in the ocean, i.e., $S_{\text {org }}$ and $S_{\text {caco3 }}$ indicate the formation/dissolution of organic matter and calcium carbonate, respectively, and $S_{\text {gas }}$ represents the gas exchange between the atmosphere and ocean. The prognostic equations of phosphate and alkalinity are:

$$
\frac{\partial s P}{\partial t}=T_{\mathrm{adv}+\operatorname{diff}}(s P)+S_{\mathrm{org}}(s P)
$$

and

$$
\frac{\partial s A L K}{\partial t}=T_{\mathrm{adv}+\mathrm{diff}}(s A L K)+S_{\mathrm{org}}(s A L K)+S_{\mathrm{caco} 3}(s A L K),
$$

respectively. From carbonate chemistry, we know that

$$
S_{\text {сасо3 }}(s \mathrm{ALK})=2 S_{\text {сасо3 }}(s \mathrm{DIC}) .
$$

From constant stoichiometry, we have the following two equations:

$$
\begin{aligned}
& S_{\text {org }}(s \mathrm{DIC})=r_{\mathrm{CP}} S_{\text {org }}(s P), \\
& S_{\text {org }}(s \mathrm{ALK})=-r_{\mathrm{NP}} S_{\text {org }}(s P) .
\end{aligned}
$$

By regarding $T_{\mathrm{adv}}$ + diff and the source/sink terms as linear operators, e.g., $r_{\mathrm{CP}} S_{\text {org }}(s P)=S_{\text {org }}\left(r_{\mathrm{CP}} s P\right)$, and knowing that $T_{\text {adv }}+\operatorname{diff}\left([s P]_{\mathrm{avr}}\right)=T_{\mathrm{adv}}+\operatorname{diff}\left([s \mathrm{DIC}]_{\mathrm{avr}}\right)=T_{\mathrm{adv}+\operatorname{diff}}\left([s \mathrm{ALK}]_{\mathrm{avr}}\right)=$ 0 , we can confirm that the prognostic equations of $\Delta C_{\text {org }}$, $\Delta C_{\text {caco3 }}$, and $\Delta C_{\text {gas }}$ become

$$
\frac{\partial \Delta C_{\text {org }}}{\partial t}=T_{\text {adv }+ \text { diff }}\left(\Delta C_{\text {org }}\right)+S_{\text {org }}(s \mathrm{DIC})-r_{\mathrm{CP}} \frac{\partial[s P]_{\mathrm{avr}}}{\partial t},
$$

$$
\frac{\partial \Delta C_{\mathrm{caco3}}}{\partial t}=T_{\mathrm{adv}+\mathrm{diff}}\left(\Delta C_{\mathrm{caco} 3}\right)+S_{\mathrm{caco} 3}(s \mathrm{DIC})-\frac{1}{2}\left(\frac{\partial[s \mathrm{ALK}]_{\mathrm{avr}}}{\partial t}+r_{\mathrm{NP}} \frac{\partial[s P]_{\mathrm{avr}}}{\partial t}\right),
$$

and

$$
\begin{aligned}
\frac{\partial \Delta C_{\text {gas }}}{\partial t}= & T_{\text {adv }+ \text { diff }}\left(\Delta C_{\text {gas }}\right)+S_{\text {gas }}(s \mathrm{DIC}) \\
& +\left\{\left(\frac{r_{\mathrm{NP}}}{2}+r_{\mathrm{CP}}\right) \frac{\partial[s P]_{\mathrm{avr}}}{\partial t}+\frac{1}{2} \frac{\partial[s A L K]_{\mathrm{avr}}}{\partial t}-\frac{\partial[s D I C]_{\mathrm{avr}}}{\partial t}\right\},
\end{aligned}
$$

respectively. When $[s P]_{\mathrm{avr}},[s \mathrm{DIC}]_{\mathrm{avr}}$, and $[s \mathrm{ALK}]_{\mathrm{avr}}$ are invariant with time, the final terms on the right-hand side become zero and the equations of $\Delta C_{\text {org }}, \Delta C_{\text {caco3 }}$, and $\Delta C_{\text {gas }}$ are written simply as

$$
\begin{aligned}
& \frac{\partial \Delta C_{\text {org }}}{\partial t}=T_{\mathrm{adv}+\operatorname{diff}}\left(\Delta C_{\mathrm{org}}\right)+S_{\mathrm{org}}(s \mathrm{DIC}), \\
& \frac{\partial \Delta C_{\mathrm{caco3}}}{\partial t}=T_{\mathrm{adv}+\operatorname{diff}}\left(\Delta C_{\mathrm{caco} 3}\right)+S_{\mathrm{caco3}}(s \mathrm{DIC}),
\end{aligned}
$$

and 


$$
\frac{\partial \Delta C_{\mathrm{gas}}}{\partial t}=T_{\mathrm{adv}+\text { diff }}\left(\Delta C_{\mathrm{gas}}\right)+S_{\mathrm{gas}}(s \mathrm{DIC}),
$$

respectively. These equations clearly indicate that the source/sink terms for $\Delta C_{\text {org }}, \Delta C_{\text {caco3 }}$, and $\Delta C_{\text {gas }}$ consist purely of $S_{\text {org }}, S_{\text {caco3 }}$, and $S_{\text {gas }}$, respectively (note that the distributions of $\Delta C_{\text {org }}, \Delta C_{\text {caco3 }}$, and $\Delta C_{\text {gas }}$ are affected by ocean transport, as well as by these source/sink terms). As described in Sarmiento and Gruber (2006), some studies have used another definition, in which the gas exchange pump is not treated explicitly and its contribution is incorporated within the other pumps (e.g., Cameron et al. 2005). As explained at the beginning of this section, the most important difference of our formulation from the previous studies is that we define $C_{\text {org }}$, $\Delta C_{\mathrm{caco3}} \Delta C_{\mathrm{gas}}$, and $\Delta C_{\mathrm{fw}}$ by the deviation form "globally averaged value" rather than "surface value." This enables us to assess the degree of surface depletion by individual carbon pumps, which can be used for evaluating the effects of the organic matter, calcium carbonate, gas exchange, and freshwater flux pumps on atmospheric $\mathrm{CO}_{2}$ concentration.

Similarly, we can decompose alkalinity as below:

$$
\Delta \mathrm{ALK}=\mathrm{ALK}-\mathrm{ALK} \text { avr }=\Delta A_{\text {org }}+\Delta A_{\text {caco3 }}+\Delta A_{\text {gas }}+\Delta A_{\mathrm{fw}},
$$

$$
\begin{aligned}
& \Delta A_{\mathrm{org}}=-\frac{r_{\mathrm{NP}}}{r_{\mathrm{CP}}} \Delta C_{\mathrm{org}}, \\
& \Delta A_{\mathrm{caco3}}=2 \Delta C_{\mathrm{caco3}}, \\
& \Delta A_{\mathrm{gas}}=s \mathrm{ALK}-[s \mathrm{ALK}]_{\mathrm{avr}}-\Delta A_{\mathrm{org}}-\Delta A_{\mathrm{caco3}}=0, \\
& \Delta A_{\mathrm{fw}}=\left(\mathrm{ALK}-[\mathrm{ALK}]_{\mathrm{avr}}\right)-\left(s \mathrm{ALK}-[s \mathrm{ALK}]_{\mathrm{avr}}\right) .
\end{aligned}
$$

Note that from the definition, $\Delta A_{\text {gas }}$ always becomes zero, which is obviously valid considering there is no air-sea exchange of alkalinity.

\section{Observational data and CMIP5 simulations}

For the carbon pump decomposition introduced above, climatological steady-state three-dimensional fields of DIC, ALK, phosphate, and salinity are required. To apply this decomposition to observational data, GLODAP climatology (Key et al. 2004) was used for DIC and ALK, and WOA climatology (Conkright et al. 2002) was referenced for phosphate and salinity in this study. The distributions of $\Delta C_{\text {org }}, \Delta C_{\text {caco3 }}$, $\Delta C_{\mathrm{fw}}, \Delta C_{\mathrm{gas}}, \Delta A_{\text {org }}, \Delta A_{\text {caco3 }}, \Delta A_{\mathrm{fw}}$, and $\Delta A_{\text {gas }}$ were calculated from the observations of DIC, ALK, $P$, and salinity by assuming constant stoichiometric ratios: $r_{\mathrm{CP}}=117$ and $r_{\mathrm{NP}}=16$ (Anderson and Sarmiento 1994). Note that the natural DIC values provided in Key et al. (2004) were used here (anthropogenic DIC was removed from the observed DIC).
The decomposition was also applied to the results of ESM simulations obtained from the CMIP5 dataset (Solomon et al. 2007). Following previous CMIP5 analysis (Shigemitsu et al. 2017; Nakamura and Oka 2019), nine CMIP5 models were used in this study: CESM1BGC (Lindsay et al. 2014), GFDL-ESM2G, GFDLESM2M (Dunne et al. 2013), HadGEM2-ES (Collins et al. 2011), IPSL-CM5A-LR, IPSL-CM5A-MR (Dufresne et al. 2013), MPI-ESM-LR, MPI-ESM-MR (Giorgetta et al. 2013), and NorESM1-ME (Bentsen et al. 2013). The choice of CMIP5 models is also the same as those of other previous studies (Bopp et al. 2013; Fu et al. 2016) except that CMCC-ESM is excluded for analysis here because of its potential possibility for century-scale drift (Bopp et al. 2013; Nakamura and Oka 2019). The monthly or annual mean outputs of DIC, ALK, phosphate, and salinity were downloaded from CMIP5 data archives (available from http://pcmdi9.llnl.gov) and interpolated into a common $1^{\circ}$ grid. Because nitrate is a sole prognostic nutrient in HadGEM2-ES, we obtained phosphate concentrations from nitrate by assuming a constant stoichiometric ratio of nitrogen to phosphorous (Anderson and Sarmiento 1994) for this model. We used the historical simulation, of which only the first ensemble member (r1i1p1) was referenced. Note that historical simulation referenced here is "concentration-driven" simulation in which atmospheric $\mathrm{CO}_{2}$ is not predicted but prescribed from the observed value. The average over the periods between 1870 and 1899 (during which the anthropogenic carbon is almost negligible) was used for the analysis.

\section{Results and discussion}

Distribution of pump components from observational data Figure 1 shows the horizontally averaged vertical distributions of each ocean carbon pump component. In Fig. 2, the vertical sections of $\Delta C_{\text {org }}, \Delta C_{\text {caco3 }}, \Delta C_{\text {gas }}$, and $\Delta C_{\mathrm{fw}}$ along the track transecting the Atlantic, Southern, and Pacific Oceans are also displayed. Figure $1 \mathrm{a}$ and $\mathrm{b}$ suggest that $\Delta C_{\text {org }}$ (red line) and $\Delta A_{\text {сасо3 }}$ (green line) are the most significant contributors to the deviation from the globally averaged values of DIC and ALK, respectively. The distribution of $\Delta C_{\text {org }}$ is determined solely from $P$ (Fig. $2 \mathrm{~b}$ ), where the organic matter pump causes depletion at the surface and enrichment in the deep ocean (red line in Fig. 1a). At the same time, this pump causes surface enrichment of $\Delta A_{\text {org }}$ and its depletion in deeper water (red line in Fig. 1b). The distribution of $\Delta A_{\text {caco3 }}$ is similar to that of ALK (Fig. 2c); its enrichment occurs at greater depths than that of $\Delta A_{\text {org }}$ because of the different dissolution profiles between organic matter and calcium carbonate (Yamanaka and Tajika 1996; Oka et al. 2008; Kwon et al. 2009). The distribution of 


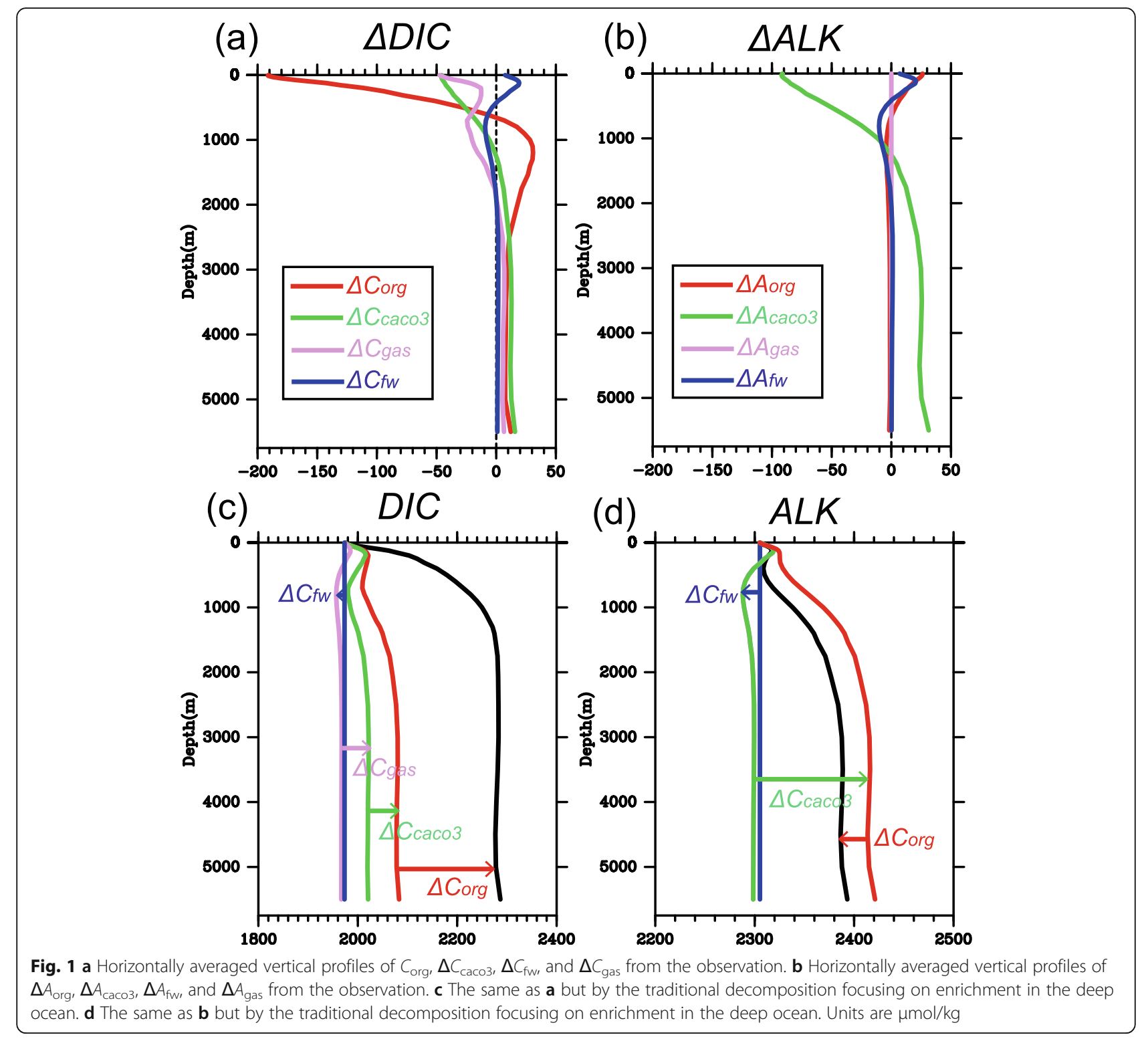

$\Delta C_{\text {gas }}$ is determined as a result of both the air-sea gas exchange of $\mathrm{CO}_{2}$ at the surface and the ocean transport within the ocean (Fig. 2d). Figure 1a shows that $\Delta C_{\text {gas }}$ is negative at the shallower depth and positive in the deeper ocean (purple line). Considering there is no source/sink term of $\Delta C_{\text {gas }}$ within the ocean (i.e., $S_{\text {gas }}$ is zero except at the surface), the enrichment of $\Delta C_{\text {gas }}$ in the deep ocean can be explained only by the transport of positive $\Delta C_{\text {gas }}$ from the ocean surface to the deep ocean. Figure $2 \mathrm{~d}$ indicates that $\Delta C_{\text {gas }}$ becomes positive mainly in the North Atlantic Ocean, whereas negative values are found in most of the Southern Ocean. This suggests that positive value of $C_{\text {gas }}$ in the deep ocean is supplied from deep-water formation area in the North Atlantic Ocean. Figure 2e confirms that the distribution of $\Delta C_{\mathrm{fw}}$ becomes the same as that of salinity and the vertical profiles of $\Delta C_{\mathrm{fw}}$ and $\Delta A_{\mathrm{fw}}$ are also the same as that of salinity (blue line in Fig. 1a, b).

In our decomposition, $C_{\text {org }}, \Delta C_{\text {caco3 }} \Delta C_{\text {gas }}$, and $\Delta C_{\mathrm{fw}}$ were defined by the deviation from "globally averaged value" rather than "surface value" as seen in Eq. (1). Alternatively, previous decompositions usually referred "surface value" as a base value; the decomposition was usually defined from the deviation from the surface value. This traditional carbon pump decomposition is also demonstrated in Fig. 1c, d. The previous decomposition clearly demonstrates the enrichment of DIC and ALK in the deep ocean by the organic and alkalinity pumps, respectively. This decomposition is useful for focusing on the enrichment in the deep ocean but not directly used for evaluating the surface depletion of DIC 


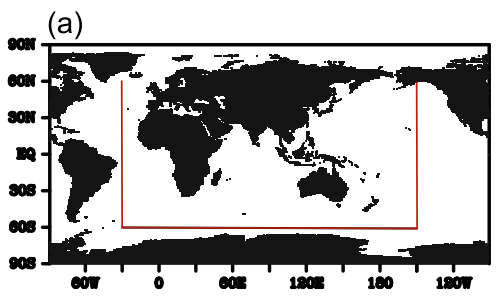

(b) $\Delta C_{\text {org }}$

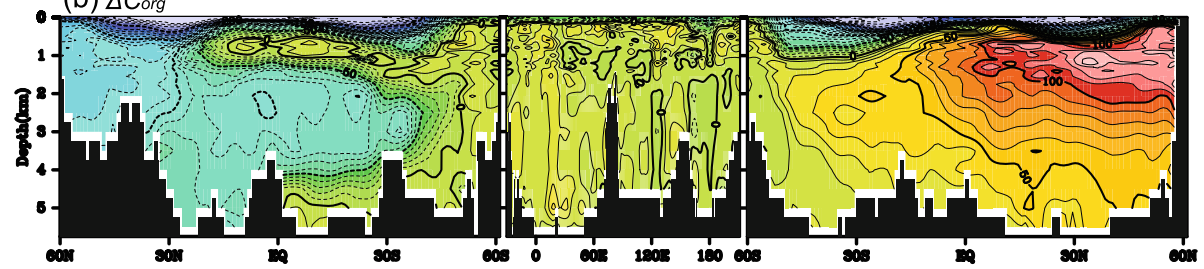

(c) $\Delta C_{\text {caco3 }}$

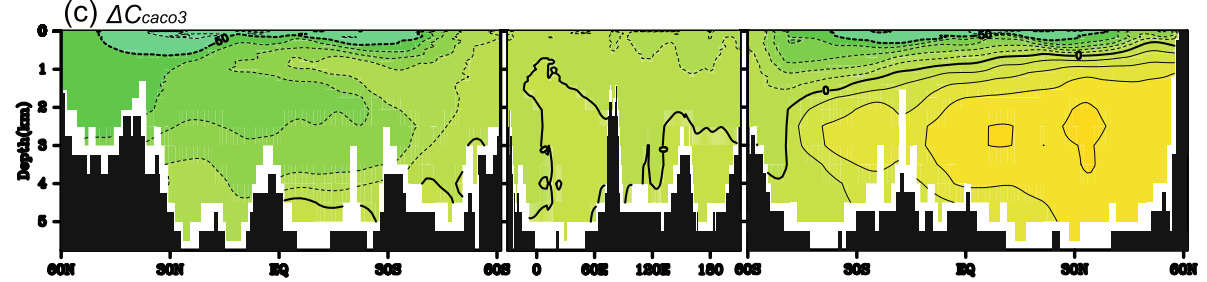

(d) $\Delta C_{\text {gas }}$

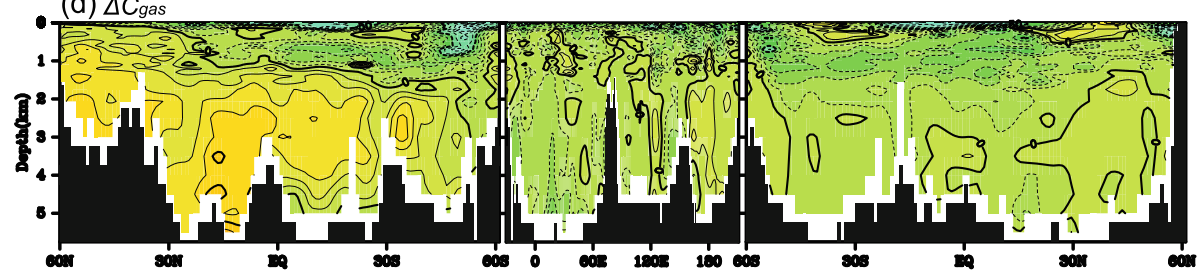

(e) $\Delta C_{f w}$

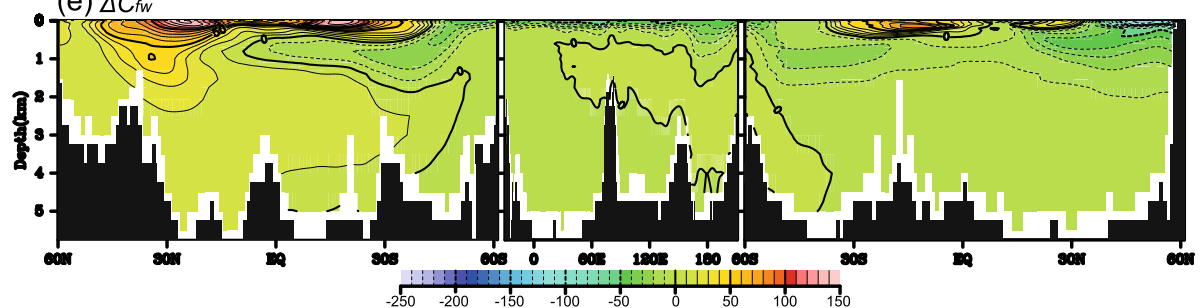

Fig. 2 a Map showing the location of vertical section with red line, which transects along $30 \mathrm{~W}$ in the Atlantic Ocean, $60 \mathrm{~S}$ in the Southern Ocean, and $150 \mathrm{~W}$ in the Pacific Ocean. The distribution of $\mathbf{b} \Delta C_{\mathrm{org},} \mathbf{c} \Delta \mathrm{C}_{\mathrm{caco3}} \mathbf{d} \Delta \mathrm{C}_{\mathrm{gas}}$, and $\mathbf{e} \Delta \mathrm{C}_{\mathrm{fw}}$ along the section shown by red line in $\mathbf{a}$ from the observation. Units are $\mu \mathrm{mol} / \mathrm{kg}$

which is important for controlling the oceanic $\mathrm{pCO}_{2}$. Contrary to previous decomposition, our decomposition can explicitly evaluate the surface depletion of DIC which will be discussed in detail below.

The surface distributions of $\Delta C_{\mathrm{org}}, \Delta C_{\mathrm{caco} 3}, \Delta C_{\mathrm{gas}}$, and $\Delta C_{\mathrm{fw}}$ are shown in Fig. 3a-d, respectively. Figure $3 \mathrm{a}$ and $\mathrm{b}$ indicate negative values for $\Delta C_{\text {org }}$ and $\Delta C_{\text {caco3 }}$ over the entire surface ocean. Note that each carbon pump component is defined such that its globally averaged value becomes zero; in the deeper ocean, they are positive, as seen in Fig. 1. Figure 3c shows that $\Delta C_{\text {gas }}$ is negative over almost the entire surface, whereas it is positive in the deeper ocean (Fig. 1a). As discussed above, the positive value in the deep ocean appears to be transported from the deep-water formation area in the northern North Atlantic Ocean (Fig. 2d). Therefore, although the observational data of $\Delta C_{\text {gas }}$ is missing over the Arctic Ocean and the northern North Atlantic Ocean, $C_{\text {gas }}$ is expected to be positive in these regions (this is indeed supported from the results of CMIP5 ESM simulations). From Fig. 3d, it can be confirmed that the surface distribution of $\Delta C_{\mathrm{fw}}$ mirrors the pattern of sea surface salinity (SSS) as a matter of course. Although not shown here, the surface distribution of $\Delta A_{\text {org }}, \Delta A_{\text {caco3 }}, \Delta A_{\mathrm{fw}}$, and $\Delta A_{\text {gas }}$ can also be discussed in the same manner. 

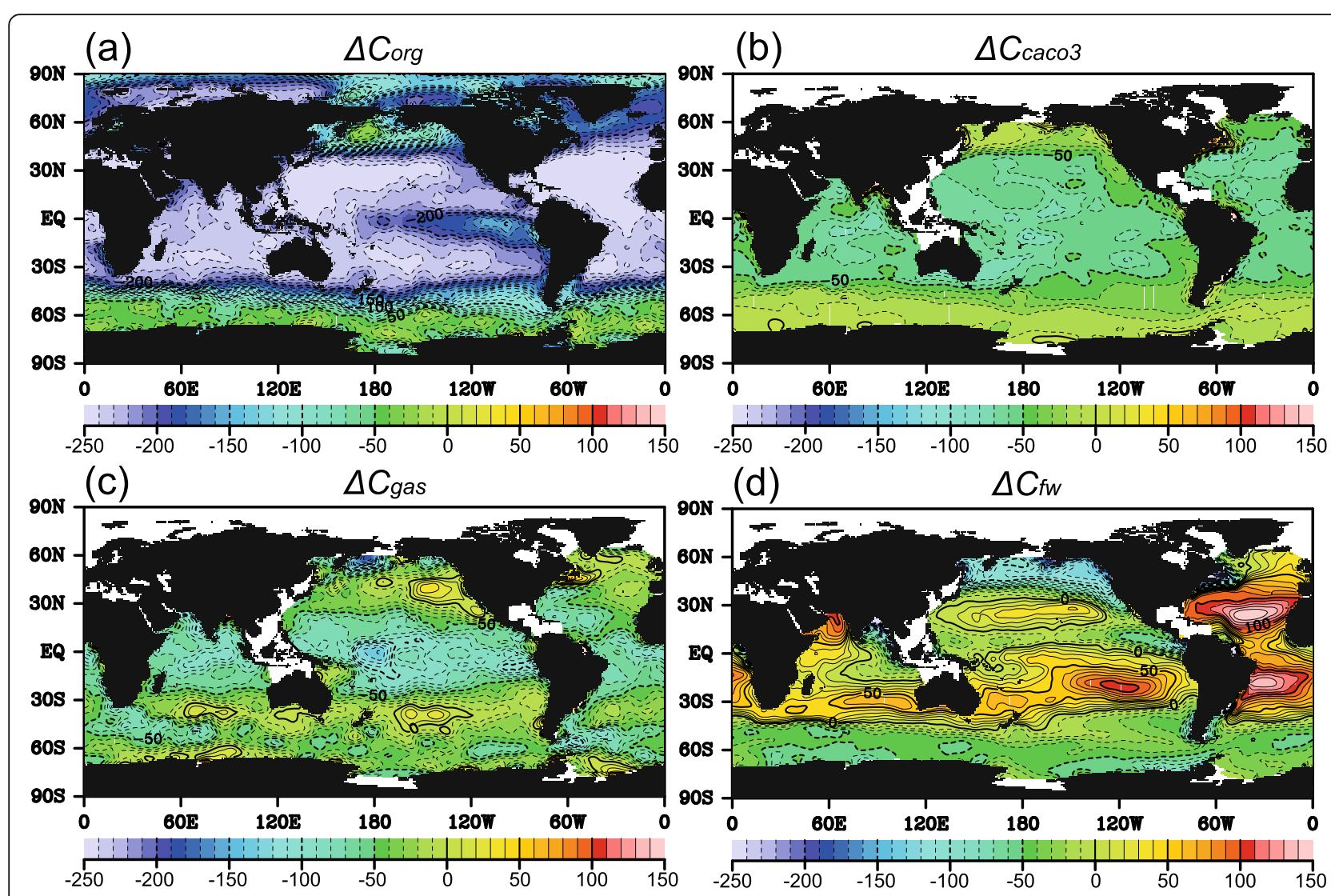

Fig. 3 Surface distribution of a $\Delta C_{\text {org, }}$ b $\Delta C_{\text {caco3, }}, \mathbf{c} \Delta C_{\text {gas }}$ and $\mathbf{d} \Delta C_{\text {fw }}$ from the observation. Units are $\mu \mathrm{mol} / \mathrm{kg}$

Effects of ocean carbon pumps on oceanic $\mathrm{pCO}_{2}$

In the case where the surface ocean and atmosphere are in equilibrium, atmospheric $\mathrm{pCO}_{2}$ becomes very close to oceanic $\mathrm{pCO}_{2}$. The processes related to gas exchange between the atmosphere and ocean are faster than the other biogeochemical processes within the ocean, and oceanic $\mathrm{pCO}_{2}$ can be regarded as being in equilibrium with atmospheric $\mathrm{pCO}_{2}$ when focusing on the climatological state of the ocean carbon cycle. Oceanic $\mathrm{pCO}_{2}$ depends on DIC and ALK, and here, we try to evaluate how oceanic $\mathrm{pCO}_{2}$ is affected by the individual ocean carbon pumps defined above.

Based on the inorganic chemistry of the carbon system, oceanic $\mathrm{pCO}_{2}$ is also controlled by temperature and salinity, and it can be expressed symbolically as below:

$$
\mathrm{pCO}_{2}=f(\mathrm{DIC}, \mathrm{ALK}, \mathrm{SST}, \mathrm{SSS}),
$$

where SST is sea surface temperature, SSS is sea surface salinity, and $f$ represents a function determined from the inorganic chemistry of the carbon system (Millero 1995; Yoshikawa et al. 2008; Oka et al. 2011b). The $\mathrm{pCO}_{2}$ distribution calculated from the observational data of DIC,
ALK, SST, and SSS are shown in Fig. 4a. Because of dependency on SST, the values tend to be larger in lower latitudes and smaller in higher latitudes. In addition, $\mathrm{pCO}_{2}$ is dependent on the distributions of DIC and ALK which we will mainly focus on. Here, we define the following $\mathrm{pCO}_{2 \text { (Pump) }}$ in order to discuss the effects of DIC and $\mathrm{ALK}$ on $\mathrm{pCO}_{2}$ :

$$
\mathrm{pCO}_{2(\text { Pump })}=f\left(\mathrm{DIC}, \mathrm{ALK},[\mathrm{SST}]_{\mathrm{sfc}},[\mathrm{SSS}]_{\mathrm{sfc}}\right) .
$$

We also define the following $\mathrm{pCO}_{2(\mathrm{NoPump})}$ for reference:

$$
\mathrm{pCO}_{2(\mathrm{NoPump})}=f\left([\mathrm{DIC}]_{\mathrm{avr}},[\mathrm{ALK}]_{\mathrm{avr}},[\mathrm{SST}]_{\mathrm{sfc}},[\mathrm{SSS}]_{\mathrm{sfc}}\right) \text {. }
$$

The pressure $\mathrm{pCO}_{2 \text { (NoPump) }}$ represents the reference $\mathrm{pCO}_{2}$ when no ocean carbon pump exists (i.e., $\Delta C_{\text {org }}=\Delta C_{\text {caco3 }}=$ $\Delta C_{\mathrm{fw}}=\Delta C_{\mathrm{gas}}=0$ and $\Delta A_{\mathrm{org}}=\Delta A_{\mathrm{caco} 3}=\Delta A_{\mathrm{fw}}=\Delta A_{\mathrm{gas}}=0$ ). The difference between these two pressures can be referenced as the total effect of ocean carbon pumps, which is defined as 


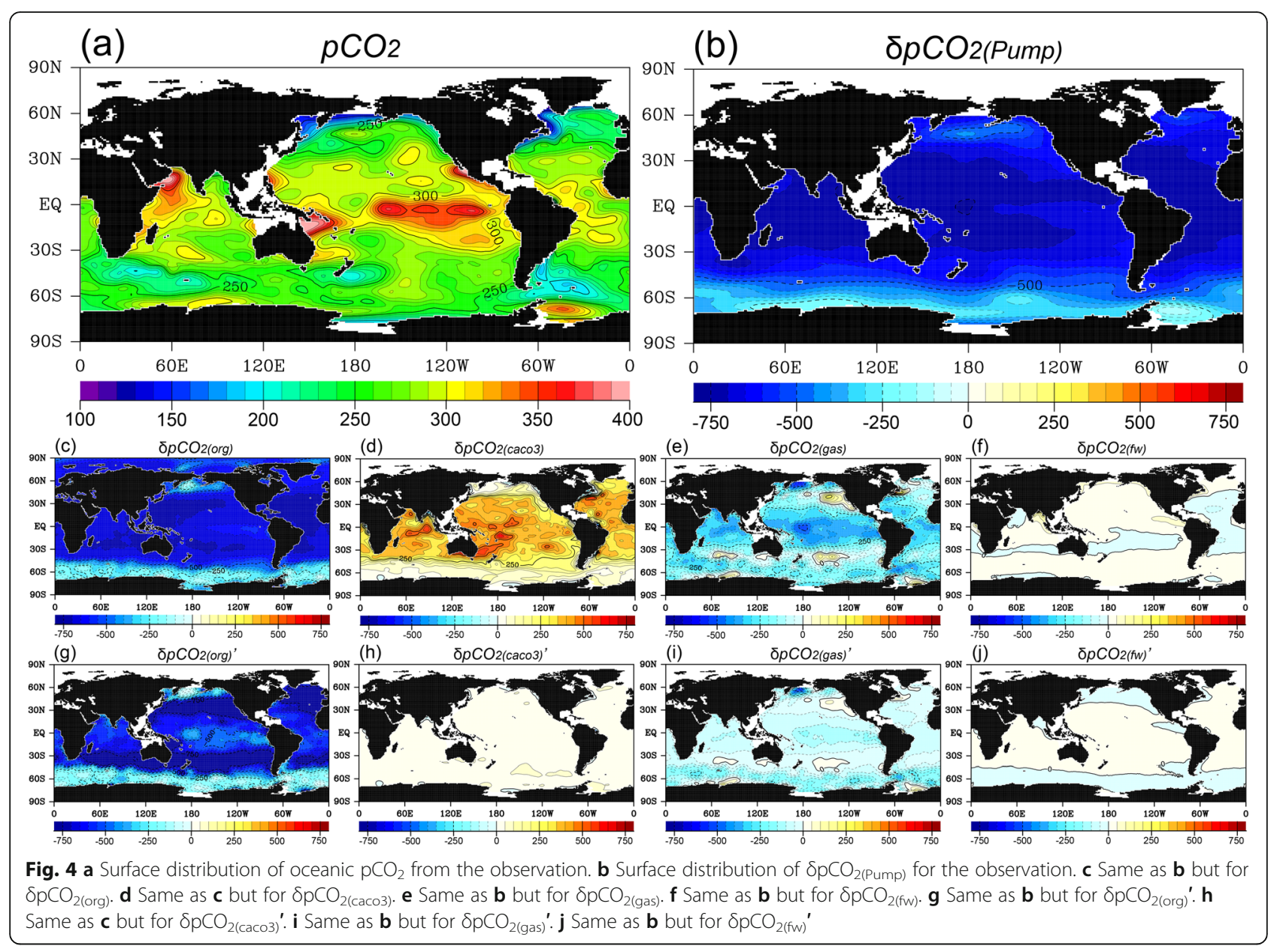

$$
\delta \mathrm{pCO}_{2(\text { Pump })}=\mathrm{pCO}_{2(\text { Pump })}-\mathrm{pCO}_{2(\text { NoPump })} .
$$

The distribution of $\delta \mathrm{pCO}_{2 \text { (Pump) }}$ is displayed in Fig. 4b. Because $\mathrm{pCO}_{2 \text { (NoPump) }}$ is a scalar value, the horizontal pattern is determined solely by that of $\mathrm{pCO}_{2 \text { (Pump) }}$. By taking the surface average of $\delta \mathrm{pCO}_{2(\mathrm{Pump})}$, the change of $\mathrm{pCO}_{2}$ caused by the ocean carbon pumps can be quantified; from the observational data, the globally averaged value of $\mathrm{pCO}_{2 \text { (Pump) }}$ (i.e., $\left[\mathrm{pCO}_{2 \text { (Pump) }}\right]_{\mathrm{sfc}}$ ) is $289 \mathrm{ppm}$, the value of $\mathrm{pCO}_{2 \text { (NoPump) }}$ is $925 \mathrm{ppm}$, and their difference (i.e., $\left[\delta \mathrm{pCO}_{2(\text { Pump })}\right]_{\mathrm{sfc}}$ ) is calculated as $-636 \mathrm{ppm}$.

The next step is to decompose $\delta \mathrm{pCO}_{2 \text { (Pump) }}$ into the contributions from each ocean pump component. One way to evaluate the individual effects of each carbon pump on oceanic $\mathrm{pCO}_{2}$ may be expressed as:

$$
\begin{aligned}
\delta \mathrm{pCO}_{2(\mathrm{org})}= & f\left([\mathrm{DIC}]_{\mathrm{avr}}+\Delta \mathrm{C}_{\mathrm{org}},[\mathrm{ALK}]_{\mathrm{avr}}\right. \\
& \left.+\Delta \mathrm{ALK}_{\mathrm{org}},[\mathrm{SST}]_{\mathrm{sfc}},[\mathrm{SSS}]_{\mathrm{sfc}}\right)-\mathrm{pCO}_{2 \text { (NoPump) }}
\end{aligned}
$$

$$
\begin{aligned}
\delta \mathrm{pCO}_{2(\text { сасо3 })=} & f\left([\mathrm{DIC}]_{\mathrm{avr}}+\Delta \mathrm{C}_{\mathrm{cac0} 3},[\mathrm{ALK}]_{\mathrm{avr}}\right. \\
& \left.+\Delta \mathrm{ALK}_{\mathrm{caco} 3},[\mathrm{SST}]_{\mathrm{sfc}},[\mathrm{SSS}]_{\mathrm{scc}}\right)-\mathrm{pCO}_{2(\mathrm{NoPump})}
\end{aligned}
$$

$$
\begin{aligned}
\delta \mathrm{pCO}_{2(\text { gas })}= & f\left([\mathrm{DIC}]_{\mathrm{avr}}+\Delta \mathrm{C}_{\mathrm{gas}},[\mathrm{ALK}]_{\mathrm{avr}}\right. \\
& \left.+\Delta \mathrm{ALK} K_{\mathrm{gas}},[\mathrm{SST}]_{\mathrm{sfc}},[\mathrm{SSS}]_{\mathrm{sfc}}\right)-\mathrm{pCO}_{2 \text { (NoPump })}
\end{aligned}
$$

$$
\begin{aligned}
\delta \mathrm{pCO}_{2(\mathrm{fw})}= & f\left([\mathrm{DIC}]_{\mathrm{avr}}+\Delta \mathrm{C}_{\mathrm{fw}},[\mathrm{ALK}]_{\mathrm{avr}}\right. \\
& \left.+\Delta \mathrm{ALK}_{\mathrm{fw}},[\mathrm{SST}]_{\mathrm{sc}},[\mathrm{SSS}]_{\mathrm{sfc}}\right)-\mathrm{pCO}_{2 \text { (NoPump) }}
\end{aligned}
$$

These expressions represent how much the oceanic $\mathrm{pCO}_{2}$ is changed from the state without ocean carbon pumps by adding the organic matter, calcium carbonate, gas exchange, and freshwater pumps, respectively. Figure $4 \mathrm{c}-\mathrm{f}$ displays the distributions of $\delta \mathrm{pCO}_{2 \text { (org) }}, \delta \mathrm{pCO}_{2 \text { (сасо3) }}, \delta \mathrm{pCO}_{2 \text { (gas) }}$, and $\delta \mathrm{pCO}_{2(\mathrm{fw})}$, respectively, estimated from the observations with using the above equations. The figures suggest 
that the organic matter pump has the dominant role in reducing $\mathrm{pCO}_{2}$. The gas exchange pump also contributes to the reduction of $\mathrm{pCO}_{2}$. On the other hand, the calcium carbonate pump contributes to an increase of $\mathrm{pCO}_{2}$ because of alkalinity changes. Although the freshwater flux pump has significant effect on the concentrations of both DIC and ALK (Fig. 1a, b; Fig. 2e; Fig. 3d), their respective effects on $\mathrm{pCO}_{2}$ are negated by each other and their combined effect on $\mathrm{pCO}_{2}$ becomes very small. As for the surface-averaged value, it is calculated that $\left[\delta \mathrm{pCO}_{2(\mathrm{org})}\right]_{\mathrm{sfc}}=-600 \mathrm{ppm},\left[\delta \mathrm{pCO}_{2 \text { (- }}\right.$ сасо3) $]_{\mathrm{sfc}}=301 \mathrm{ppm},\left[\delta \mathrm{pCO}_{2(\mathrm{gas})}\right]_{\mathrm{sfc}}=-246 \mathrm{ppm}$, and $\left[\delta \mathrm{pCO}_{2(\mathrm{fw})}\right]_{\mathrm{sfc}}=-5 \mathrm{ppm}$. In contrast to DIC and ALK, the total change of $\mathrm{pCO}_{2}$ cannot be represented by linear combinations of the four carbon pumps (i.e., $\delta \mathrm{pCO}_{2(\text { Pump })} \neq \delta \mathrm{pCO}_{2 \text { (org) }}+\delta \mathrm{pCO}_{2 \text { (caco3) }}+\delta \mathrm{pCO}_{2 \text { (gas) }}+$ $\left.\delta \mathrm{pCO}_{2(\mathrm{fw})}\right)$. This is because of the nonlinearity of function " $f$ " of Eq. (23), which makes it difficult to obtain a simple decomposition of $\delta \mathrm{pCO}_{2 \text { (Pump) }}$ into the individual contributions from each ocean pump component.

\section{Nonlinearity of ocean carbon chemistry}

Instead of using Eqs. (27)-(30), the effects of each carbon pump on $\mathrm{pCO}_{2}$ can also be evaluated as below:

$$
\delta \mathrm{pCO}_{2(\mathrm{org})}^{\prime}=\mathrm{pCO}_{2(\mathrm{Pump})}-f\left(\mathrm{DIC}-\Delta C_{\mathrm{org}}, \mathrm{ALK}-\Delta A_{\mathrm{org}},[\mathrm{SST}]_{\mathrm{sfc}},[\mathrm{SSS}]_{\mathrm{sfc}}\right),
$$

$\delta \mathrm{pCO}_{2(\text { сасо3 })}^{\prime}=\mathrm{pCO}_{2(\text { (Pump) }}-f\left(\mathrm{DIC}-\Delta C_{\mathrm{caco} 3}, \mathrm{ALK}-\Delta A_{\mathrm{caco} 3},[\mathrm{SST}]_{\mathrm{sfc}},[\mathrm{SSS}]_{\mathrm{sfc}}\right)$,

$\delta \mathrm{pCO}_{2(\text { gas })}^{\prime}=\mathrm{pCO}_{2(\text { (Pump) }}-f\left(\mathrm{DIC}-\Delta C_{\mathrm{gas}}, \mathrm{ALK}-\Delta A_{\mathrm{gas}},[\mathrm{SST}]_{\mathrm{sfc}},[\mathrm{SSS}]_{\mathrm{sfc}}\right)$,

$\delta \mathrm{pCO}_{2(\mathrm{fw})}^{\prime}=\mathrm{pCO}_{2(\mathrm{Pump})}-f\left(\mathrm{DIC}-\Delta C_{\mathrm{fw}}, \mathrm{ALK}-\Delta A_{\mathrm{fw}},[\mathrm{SST}]_{\mathrm{sfc}},[\mathrm{SSS}]_{\mathrm{sfc}}\right)$

The above estimates are based on the changes in oceanic $\mathrm{pCO}_{2}$ when the organic matter, calcium carbonate, gas exchange, and freshwater pumps are removed from the present state of the ocean carbon pump, respectively. Figures $4 \mathrm{~g}-\mathrm{j}$ display the distributions of $\delta \mathrm{pCO}_{2 \text { (org) }}{ }^{\prime}, \delta \mathrm{pCO}_{2(\text { caco3) }}{ }^{\prime}, \delta \mathrm{pCO}_{2 \text { (gas) }}{ }^{\prime}$, and $\delta \mathrm{pCO}_{2(\mathrm{fw})}$ ', respectively. They are similar to previous estimate in Fig. 4c-f but not the same; the values here tend to be moderate compared with those from previous estimate. From Eqs. (31)-(34), it can be calculated that $\left[\delta \mathrm{pCO}_{2 \text { (org) }}{ }^{\prime}\right]_{\mathrm{sfc}}=-560 \mathrm{ppm},\left[\delta \mathrm{pCO}_{2(\text { сасо3) })^{\prime}}\right]_{\mathrm{sfc}}=28$ $\mathrm{ppm},\left[\delta \mathrm{pCO}_{2(\mathrm{gas})}\right]_{\mathrm{sfc}}=-80 \mathrm{ppm}$, and $\left[\delta \mathrm{pCO}_{2(\mathrm{fw})}{ }^{\prime}\right]_{\mathrm{sfc}}=$ $-0.3 \mathrm{ppm}$. This suggests that the organic matter pump is dominant, as established by the previous estimates from Eqs. (27)-(30); however, its absolute value is somewhat smaller (i.e., $\left[\delta \mathrm{pCO}_{2(\mathrm{org})}{ }^{\prime}\right]_{\mathrm{sfc}}=-560$ and $\left.\left[\delta \mathrm{pCO}_{2(\mathrm{org})}\right]=-600 \mathrm{ppm}\right)$. Furthermore, the difference is more significant for the other carbon pumps, especially for the calcium carbonate pump; this is estimated at only $28 \mathrm{ppm}$, whereas the previous estimate was 301 $\mathrm{ppm}$. Such a difference also arises from the nonlinearity of function " $f$."

\section{State dependence about effects of ocean carbon pumps on oceanic $\mathrm{pCO}_{2}$}

The abovementioned difference in the evaluation of $\mathrm{pCO}_{2}$ (i.e., the difference between Eqs. (27)-(30) and Eqs. (31)-(34)) can be understood easily from Fig. 5, which explicitly shows the nonlinearity of function " $f$." Figure $5 \mathrm{a}$ and $\mathrm{b}$ visually demonstrate the estimations based on Eqs. (27)-(30) and Eqs. (31)-(34), respectively. The contours in the figure indicate the oceanic $\mathrm{pCO}_{2}$ as a function of DIC and ALK under a temperature of $18.16^{\circ} \mathrm{C}$ and salinity of $34.59 \mathrm{psu}$, which are $[\mathrm{SST}]_{\mathrm{sfc}}$ and $[\mathrm{SSS}]_{\mathrm{sfc}}$ of the observation. These contours can be used as a measure of the impact of each carbon pump on $\mathrm{pCO}_{2}$. Due to the nonlinearity of function $f$, the contour interval becomes denser for higher DIC. The figure displays the vectors which represent ocean carbon pumps: the organic matter, calcium carbonate, gas exchange, and freshwater flux pumps are expressed as red, green, purple, and blue vectors, respectively. The red, green, purple, and blue vectors are defined from surface depletion of DIC and ALK by each carbon pump: i.e., $\left(\left[\Delta C_{\text {org }}\right]_{\mathrm{sfc}},\left[\Delta A_{\text {org }}\right]_{\mathrm{sfc}}\right)$, $\left(\left[\Delta C_{\text {caco3 }}\right]_{\mathrm{sfc}},\left[\Delta A_{\text {caco } 3}\right]_{\mathrm{sfc}}\right), \quad\left(\left[\Delta C_{\mathrm{gas}}\right]_{\mathrm{sfc}},\left[\Delta A_{\mathrm{gas}}\right]_{\mathrm{sfc}}\right)$, and $\left(\left[\Delta C_{\mathrm{fw}}\right]_{\mathrm{sfc}},\left[\Delta A_{\mathrm{fw}}\right]_{\mathrm{sfc}}\right)$, respectively. Also, note that the globally averaged concentrations are represented as a solid circle ([DIC $]_{\mathrm{avr}}$ and $[\mathrm{ALK}]_{\mathrm{avr}}$ ) and the open circle indicates the surface concentrations ([DIC $]_{\mathrm{sfc}}$ and $[\mathrm{ALK}]_{\mathrm{sfc}}$ ). In the first evaluation (i.e., Eqs. (27)-(30)), the "no-pump state" is selected as the reference. In this case, the starting point of the vectors is set at the globally averaged value of DIC and ALK in the figure. Based on this figure, $\left[\delta \mathrm{pCO}_{2(\mathrm{org})}\right]_{\mathrm{sfc}},\left[\delta \mathrm{pCO}_{2 \text { (сасо3) }}\right]_{\mathrm{sfc}}$, $\left[\delta \mathrm{pCO}_{2(\mathrm{gas})}\right]_{\mathrm{sfc}}$, and $\left[\delta \mathrm{pCO}_{2(\mathrm{fw})}\right]_{\mathrm{sfc}}$ are measured from the differences in the contour values between the start and ends of the red, green, purple, and blue vectors, respectively (Fig. 5a). On the other hand, in the second evaluation (i.e., Eqs. (31)-(34)), the reference state is the present ocean, and thus, the ends of the vectors are set at the surface average value of DIC and ALK (Fig. 5b). Because the contour interval is relatively sparse around this reference state, the evaluated values for $\left[\delta \mathrm{pCO}_{2(\mathrm{org})}{ }^{\prime}\right]_{\mathrm{sfc}}$, $\left[\delta \mathrm{pCO}_{2(\mathrm{caco3})}\right]_{\mathrm{sfc}},\left[\delta \mathrm{pCO}_{2(\mathrm{gas})}{ }^{\prime}\right]_{\mathrm{sfc}}$, and $\left[\delta \mathrm{pCO}_{2(\mathrm{fw})}{ }^{\prime}\right]_{\mathrm{sfc}}$ become more moderate than in the first evaluation. Thus, in spite of the fact that the vectors used for the analysis are common between these two evaluations, their contributions to $\mathrm{pCO}_{2}$ are dependent on the selected reference state (i.e., start/end points of the vectors) because of the 

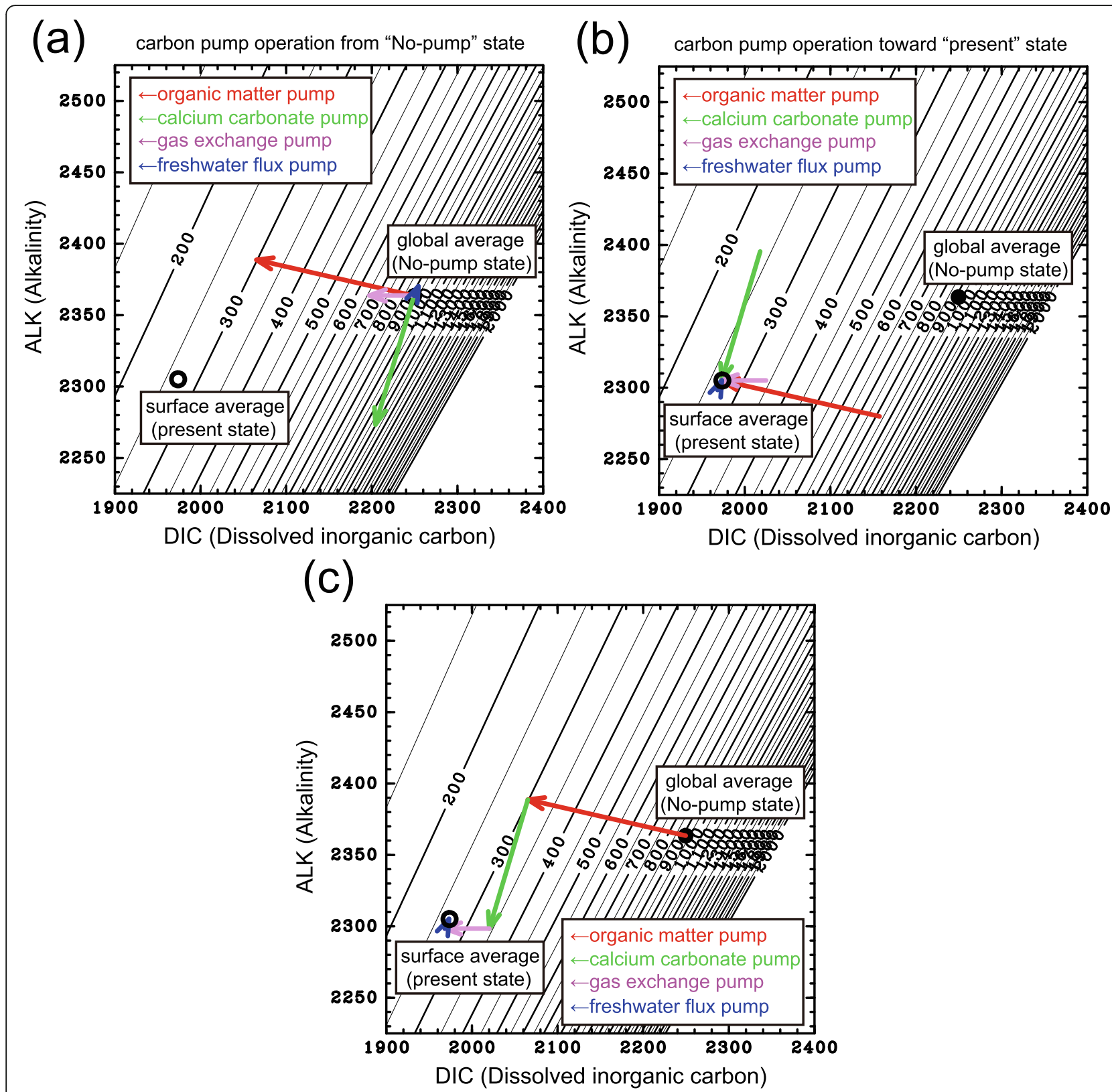

Fig. 5 Effects of the ocean carbon pumps on oceanic $\mathrm{pCO}_{2}$ from the observation: the reference state is a "no-pump" state and $\mathbf{b}$ "present" state. c Vector diagrams of the ocean carbon pumps from the observation. The contours show oceanic $\mathrm{PCO}_{2}$ as a function of DIC and ALK calculated under a temperature of $18.16^{\circ} \mathrm{C}$ and salinity of $34.59 \mathrm{psu}$. Solid and open circles represent averaged values over the global (i.e., [DIC $]_{\text {avr }}$ and $\left.[\mathrm{ALK}]_{\mathrm{avr}}\right)$ and surface (i.e., $[\mathrm{DIC}]_{\mathrm{sfc}}$ and $\left.[\mathrm{ALK}]_{\mathrm{sfc}}\right)$ oceans, respectively. Red, green, purple, and blue vectors are defined as $\left(\left[\Delta C_{\text {org }}\right]_{\mathrm{sfc}}\left[\Delta A_{\text {org }}\right]_{\mathrm{sfc}}\right)$, $\left(\left[\Delta C_{\text {caco } 3}\right]_{\mathrm{sfc}}\left[\Delta A_{\text {caco } 3}\right]_{\mathrm{sfc}}\right),\left(\left[\Delta C_{\mathrm{gas}}\right]_{\mathrm{sfc}}\left[\Delta A_{\mathrm{gas}}\right]_{\mathrm{sfc}}\right)$, and $\left.\left(\left[\Delta C_{\mathrm{fw}}\right]_{\mathrm{sfc}}, \Delta A_{\mathrm{fw}}\right]_{\mathrm{sfc}}\right)$, respectively. Units of the lateral and vertical axes are $\mu \mathrm{mol} / \mathrm{kg}$. The contour interval is $50 \mathrm{ppm}$, and contours larger than $2000 \mathrm{ppm}$ are omitted

nonlinearity of function " $f$ " (i.e., the unequally spaced contour intervals). In various sensitivity simulations, previous studies have reported that changes in atmospheric $\mathrm{pCO}_{2}$ are difficult to be decomposed linearly into separate factors (Cameron et al. 2005; Yoshikawa et al. 2008; Oka et al. 2011b; Chikamoto et al. 2012; Kobayashi et al. 2015); this is also largely attributable to the nonlinearity of " $f$."

\section{Vector diagram of ocean carbon pump}

The decomposition of DIC and ALK into pump components is clearly defined by Eqs. (1)-(5) and (18)-(22), respectively. However, their effects on $\mathrm{pCO}_{2}$ are more difficult to quantify because of the nonlinearity of function "f." Here, the vector diagram analysis is introduced (Baes 1982; Volk and Hoffert 1985), which can provide a 
clearer evaluation of the individual effects of each carbon pump on $\mathrm{pCO}_{2}$.

The vector diagram illustrates the quantitative impact of each carbon pump on oceanic $\mathrm{pCO}_{2}$, as shown in Fig. 5c, in which the organic matter, calcium carbonate, gas exchange, and freshwater flux pumps are again expressed as red, green, purple, and blue vectors, respectively. The difference from Fig. 5a and $b$ is that the starting or endpoints of individual vectors are not located in the same point but the vectors line up in order and are connected together from the solid circle $\left([\mathrm{DIC}]_{\mathrm{avr}},[\mathrm{ALK}]_{\mathrm{avr}}\right)$ to the open circle $\left([\mathrm{DIC}]_{\mathrm{sfc}},[\mathrm{ALK}]_{\mathrm{sfc}}\right)$. Note that decompositions of DIC and ALK into pump components are linear as confirmed from Eqs. (1) and (18), respectively. This means that the solid circle $\left([\mathrm{DIC}]_{\mathrm{avr}},[\mathrm{ALK}]_{\mathrm{avr}}\right)$ and the open circle $\left([\mathrm{DIC}]_{\mathrm{sfc}},[\mathrm{ALK}]_{\mathrm{scc}}\right)$ can be always strictly connected by combinations of four carbon pumps.

Figure $5 \mathrm{c}$ clearly demonstrates how the carbon pumps operate and affect the oceanic $\mathrm{pCO}_{2}$. In the case of no carbon pump, DIC and ALK become uniform everywhere and their surface values become the same as the globally averaged concentrations. With no ocean carbon pump, Fig. $5 \mathrm{c}$ suggests that $\mathrm{pCO}_{2}$ is around $900 \mathrm{ppm}$ (i.e., a solid circle lies on the contour of $900 \mathrm{ppm}$ ). The red vector (i.e., organic matter pump) accounts for a considerable proportion of $\mathrm{pCO}_{2}$ depletion. Although the green vector (i.e., carbonate pump) has the secondlargest magnitude, its effect on $\mathrm{pCO}_{2}$ is much smaller than that of the red vector because the direction of the green vector is aligned more along the $\mathrm{pCO}_{2}$ contours. The blue vector (i.e., freshwater pump) has very little effect on $\mathrm{pCO}_{2}$ despite the large spatial variation of $\Delta C_{\mathrm{fw}}$ (Fig. 2e; Fig. 3d). The purple vector (i.e., gas exchange pump) is oriented near perpendicular to the $\mathrm{pCO}_{2}$ contours, and thus, it has some effect on $\mathrm{pCO}_{2}$ although its magnitude is not large. It is demonstrated here that the vector diagram can display the individual contributions of the carbon pumps to $\mathrm{pCO}_{2}$ in an easily comprehensible manner without omitting the abovementioned nonlinear dependency.

\section{Application to CMIP5 simulations}

In the same manner as for the observational data, the decomposition of the ocean carbon pumps was applied to the CMIP5 ESM simulations; the climatological three-dimensional fields of DIC, ALK, phosphate, and salinity obtained from the CMIP5 outputs were utilized for this decomposition. As mentioned in the "Methods" section, nine CMIP5 models were used here; their vertical profiles of $\Delta C_{\mathrm{org}}, \Delta C_{\text {caco3}}, \Delta C_{\mathrm{gas}}$, and $\Delta C_{\mathrm{fw}}$ are displayed in Fig. 6. Although the formulation of the incorporated ocean biogeochemical processes is different among the models (Bopp et al. 2001; Nakamura and Oka 2019), all the model results captured the overall pattern of the observation (black line). Interestingly, the CMIP5 model mean (i.e., average of nice CMIP5 model results; shown as gray line in Fig. 6) tends to show better agreement with the observation than the individual model results (especially for $\Delta C_{\text {org }}$ ) as seen in other climate variables (Phillips and Gleckler 2006). As for the CMIP5 model mean, the surface distributions of $\Delta C_{\text {org }}$, $\Delta C_{\text {caco3 }}, \Delta C_{\text {gas }}$, and $\Delta C_{\mathrm{fw}}$ are shown in Fig. $7 \mathrm{a}-\mathrm{d}$, respectively. These figures also indicate that the model captures the overall pattern of the observation (Fig. 3). Note that $\Delta C_{\text {gas }}$ is positive in the Arctic and northern North Atlantic Oceans where the observational data is missing; this supports the previously mentioned explanation that positive $\Delta C_{\text {gas }}$ observed in the deeper ocean (Fig. 1a) is transported from the northern North Atlantic and Arctic Oceans.

Based on the obtained decomposition of DIC and ALK into the four carbon pump components, the vector diagrams for the CMIP5 models are displayed in Fig. 8. Together with individual model results (Fig. 8c-k), the observation (Fig. 8a same as Fig. 5c) and the CMIP5 model mean (Fig. $8 \mathrm{~b}$ ) are also shown in the figure. In all the models, the simulated surface average concentrations of DIC and ALK (i.e., ([DIC $]_{\mathrm{sfc}}$, $[\mathrm{ALK}]_{\mathrm{sfc}}$ ); open circles in Fig. 8) are located around the $300 \mathrm{ppm}$ contour value, which agrees with the observation (this agreement is guaranteed from the experimental design of the CMIP5 historical simulation, in which the atmospheric $\mathrm{CO}_{2}$ concentration is prescribed). In the same time, the figures also show that they are separately distributed along the $300 \mathrm{ppm}$ contour line, suggesting that the carbon pumps operate differently among the models. Figure $8 \mathrm{c}-\mathrm{k}$ illustrate how the organic matter, calcium carbonate, gas exchange, and freshwater carbon pumps are operating in the individual models by the red, green, purple, and blue vectors, respectively. The individual effects of these four ocean carbon pumps on the surface $\mathrm{pCO}_{2}$ can also be measured from the difference in the contour values between the start and end of each vector. In the same way as the observational data, Fig. 8 clearly visualizes the individual effects of the four ocean carbon pumps on the surface $\mathrm{pCO}_{2}$ in each CMIP5 model, which demonstrates that the vector diagram is a useful and simple diagnosis for ocean carbon pumps of each CMIP5 model.

\section{Vector diagram as a tool for model evaluation and comparison}

Because the carbon pump components can be decomposed linearly (Eqs. (1) and (18)), the differences in $\triangle \mathrm{DIC}$ and $\triangle \mathrm{ALK}$ between the models and the observation can also be decomposed into the four carbon pump components. For comparing the models with the observation more closely, Fig. 9 is presented. In this figure, 

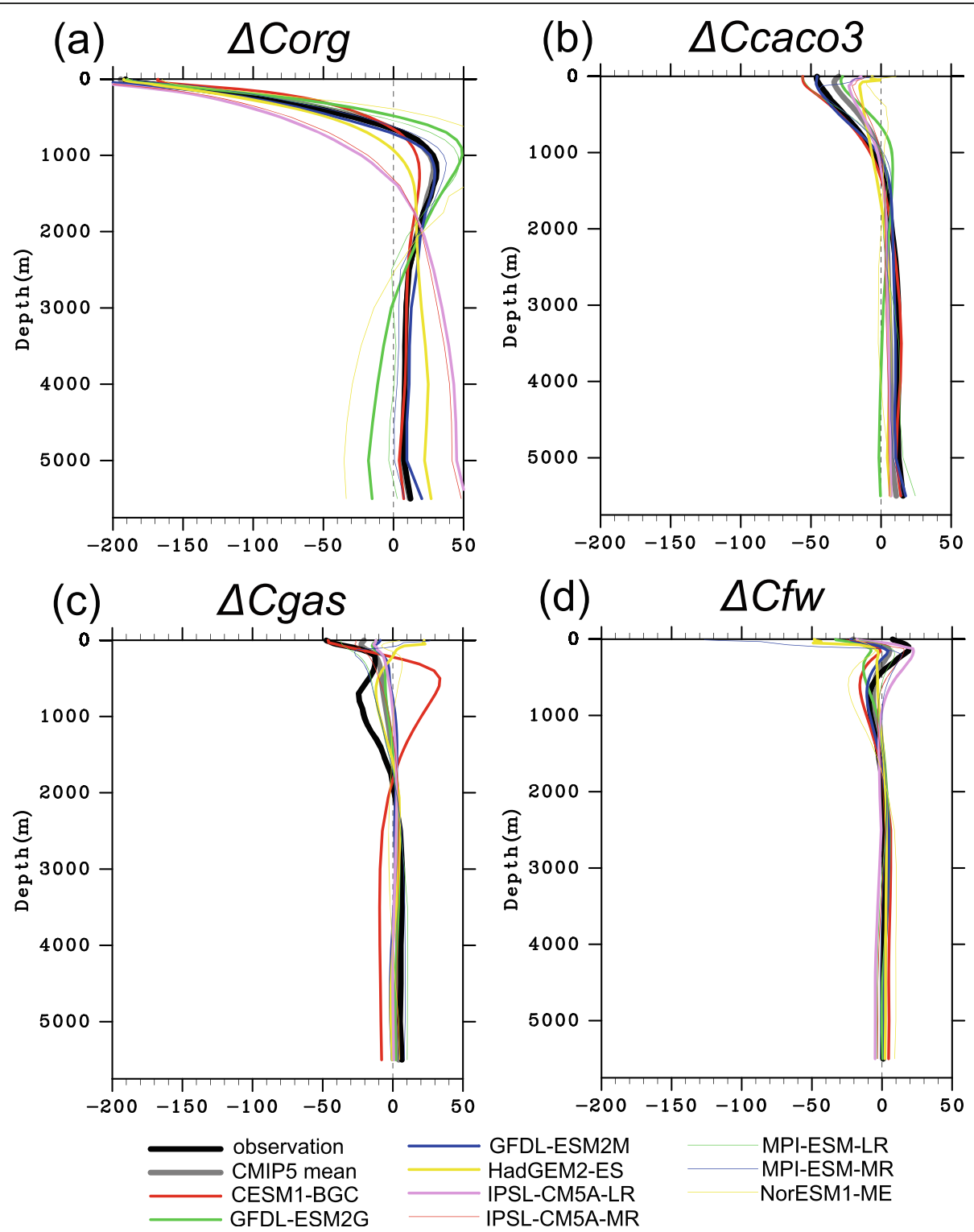

Fig. 6 Horizontally averaged vertical profiles of $\mathbf{a} C_{\mathrm{org}}, \mathbf{b} \Delta \mathrm{C}_{\mathrm{caco},}, \mathbf{c} \Delta \mathrm{C}_{\mathrm{fw},}$ and $\mathbf{d} \Delta \mathrm{C}_{\mathrm{gas},}$ from the observation and CMIP5 simulations. Units are $\mu \mathrm{mol} / \mathrm{kg}$

the surface concentrations in the model and observation (two open circles) are connected by the four pump vectors; here, the vectors are defined in the form of the differences between the observation and the models. In other words, the vector of Fig. 9 represents the model bias of each carbon component against the observation.

As for the CMIP5 model mean (Fig. 9b), the calcium carbonate pump (green arrow) is somewhat weaker than the observation, which is compensated by the weaker gas exchange pump (purple arrow). The freshwater flux pump (blue arrow) also shows fresher bias, but its contribution to $\mathrm{pCO}_{2}$ is small. Bias of organic matter pump (red arrow) is small with regard to the CMIP5 model mean. As for individual CMIP5 model results, they are also summarized in Fig. 9c-k. The organic matter pump has the largest model spread, which confirms that the small bias of the model mean is a result of cancellation between individual model biases. It is worthy to note that the strength of the organic matter pump is not simply determined from the ocean net primary production (NPP) or export production (EP). For example, although it was reported that GFDL-ESM2M has the most largest NPP among the other models (Bopp et al. 2013), Fig. 9e shows that this model has the significant weaker bias of the organic matter pump. This is because the organic matter pump is controlled not only by NPP/EP but also by the ocean transport. For example, the stronger upwelling tends to increase surface phosphate concentration, which means that the organic matter pump tends to be weaker. At the same time, the stronger upwelling 


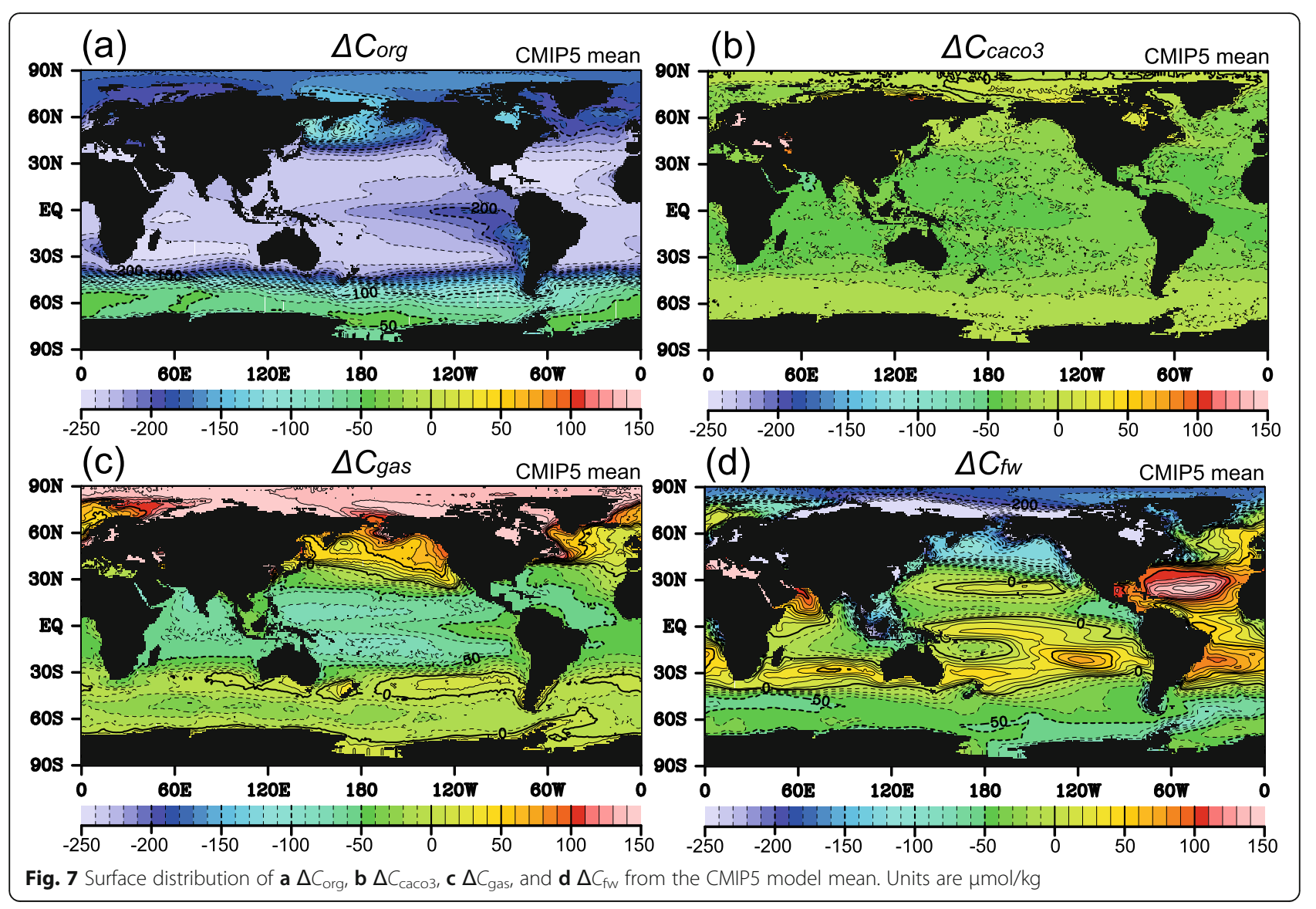

also causes the larger NPP/EP, which in turn reduces the surface phosphate concentration contributing to the strengthening of the carbon pump. Therefore, the strength of the organic matter pump is controlled under the balance between NPP/EP and the ocean transport. The figure suggests that all the models have significant fresher bias of freshwater flux pump. It is known that CMIP5 models have systematic fresher salinity bias especially over the subtropical gyre in the South Atlantic Ocean (Mecking et al. 2017), which appears to cause such systematic bias of the freshwater flux pump. All the models except CESM1-BGC, GFDL-ESM2M, and MPIESM-LR show weaker bias of calcium carbonate pump. The reason for this weaker bias appears to come from various reasons depending on models. For example, GFDL-ESM2G and NorESM1-ME have shallower maximum of $\Delta C_{\text {сасо3 }}$ than the observation (Fig. 6b), which makes the calcium carbonate pump weaker (Yamanaka and Tajika 1996; Oka et al. 2008). IPSL-CM5A-LA and IPSL-CM5A-MR have the weaker bias of the carbonate pump in spite of their stronger bias of the organic matter pump, which implies that their rain ratio is smaller. As for the gas exchange pump, the models tend to have weaker bias. This weaker bias is considered to be a result of the compensation for weaker bias of the sum of remaining three carbon pumps (mainly due to weaker bias of calcium carbonate pump). Because the atmospheric $\mathrm{pCO}_{2}$ level is prescribed in the model from the experimental design of CMIP5 historical simulation, all the models are forced to be located around the specified $\mathrm{pCO}_{2}$ level (around $300 \mathrm{ppm}$ contour line in Fig. 9a). This adjustment is done by the air-sea gas exchange; namely, the gas exchange pump works in such a way that the model's open circle becomes located close to $300 \mathrm{ppm} \mathrm{pCO}_{2}$ contour line in Fig. 9. Therefore, if the total effects of three carbon pumps have a weaker bias, the gas exchange pump needs to compensate such bias by adjusting its own strength to be also weaker.

Note that the difference in two open circles is not fully explained from the combination of four carbon pumps in Fig. 9 (i.e., the end point of blue vector is not located at the model's open circle). This is simply because the globally averaged values of DIC and ALK (i.e., ([DIC $]_{\mathrm{avr}}$, $[A L K]_{\text {avr }}$ ); solid circles in Fig. 8) are not the same as those of the observation. In other words, the difference between the end point of blue vector and the model's open circle corresponds to the difference in $\left([\mathrm{DIC}]_{\mathrm{avr}}\right.$, $\left.[\mathrm{ALK}]_{\mathrm{avr}}\right)$ between the model and the observation. The 

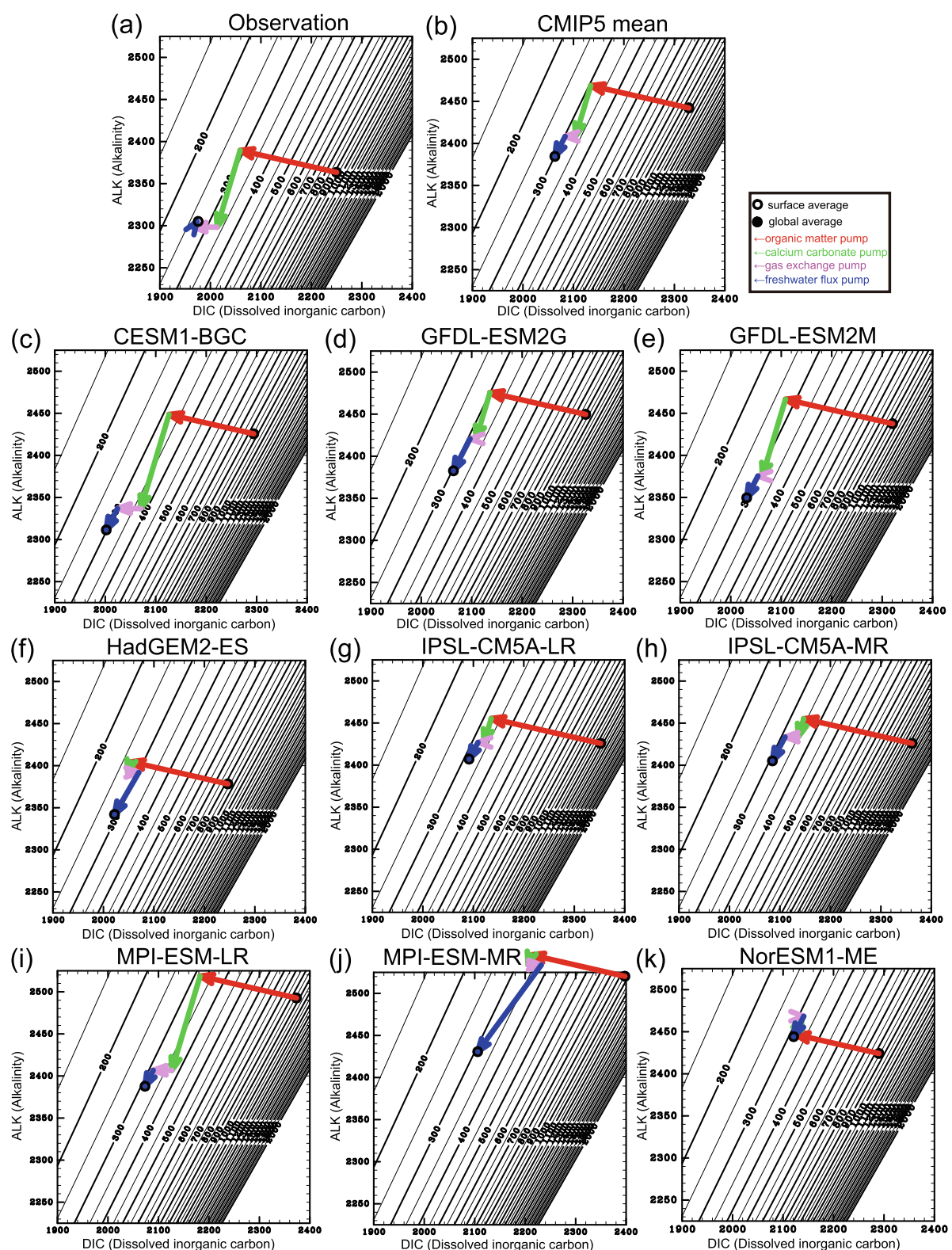

Fig. 8 Vector diagrams of the ocean carbon pumps from a the observation and $\mathbf{b}-\mathbf{k}$ CMIP5 simulations: b CMIP5 model mean, c CESM1-BGC, d GFDL-ESM2G, e GFDL-ESM2M, f HadGEM2-ES, g IPSL-CM5A-LR, h IPSL-CM5A-MR, i MPI-ESM-LR, j MPI-ESM-MR, and $\mathbf{k}$ NorESM1-ME. The contours show oceanic $\mathrm{PCO}_{2}$ as a function of DIC and ALK calculated under temperature of $18.16^{\circ} \mathrm{C}$ and salinity of $34.59 \mathrm{psu}$. Solid and open circles represent averaged values over the global (i.e., $[\mathrm{DIC}]_{\mathrm{avr}}$ and $[\mathrm{ALK}]_{\mathrm{avr}}$ ) and surface (i.e., $[\mathrm{DIC}]_{\mathrm{sfc}}$ and $[\mathrm{ALK}]_{\mathrm{sfc}}$ ) oceans, respectively. Red, green, purple, and blue vectors are defined as $\left(\left[\Delta C_{\text {org }}\right]_{\text {sfc }}\left[\Delta A_{\text {org }}\right]_{\mathrm{sfc}}\right),\left(\left[\Delta C_{\text {caco } 3}\right]_{\mathrm{sfc}},\left[\Delta A_{\text {caco } 3}\right]_{\mathrm{sfc}}\right),\left(\left[\Delta C_{\mathrm{gas}}\right]_{\mathrm{sfc}},\left[\Delta A_{\mathrm{gas}}\right]_{\mathrm{sfc}}\right)$, and $\left(\left[\Delta C_{\mathrm{fw}}\right]_{\mathrm{sfc}},\left[\Delta A_{\mathrm{fw}}\right]_{\mathrm{sfc}}\right)$, respectively. Units of the lateral and vertical axes are $\mu \mathrm{mol} / \mathrm{kg}$. The contour interval is $50 \mathrm{ppm}$, and contours larger than $2000 \mathrm{ppm}$ are omitted

CMIP5 models tend to show the larger values of globally averaged DIC and ALK than the observation. This difference originates from initial conditions of CMIP5 historical simulation; the reason for the larger initial values may come partly from the fact that models were usually spin up under recent conditions (anthropogenic carbon is included therein) rather than the condition before the year 1860 .

\section{Conclusions}

In this study, the decomposition of ocean carbon pumps into four components was introduced and the individual effects of each component on the ocean surface $\mathrm{pCO}_{2}$, which is in balance with atmospheric $\mathrm{CO}_{2}$ concentration, were quantified using a vector diagram. In the presented formulation, dissolved carbon (and alkalinity) 


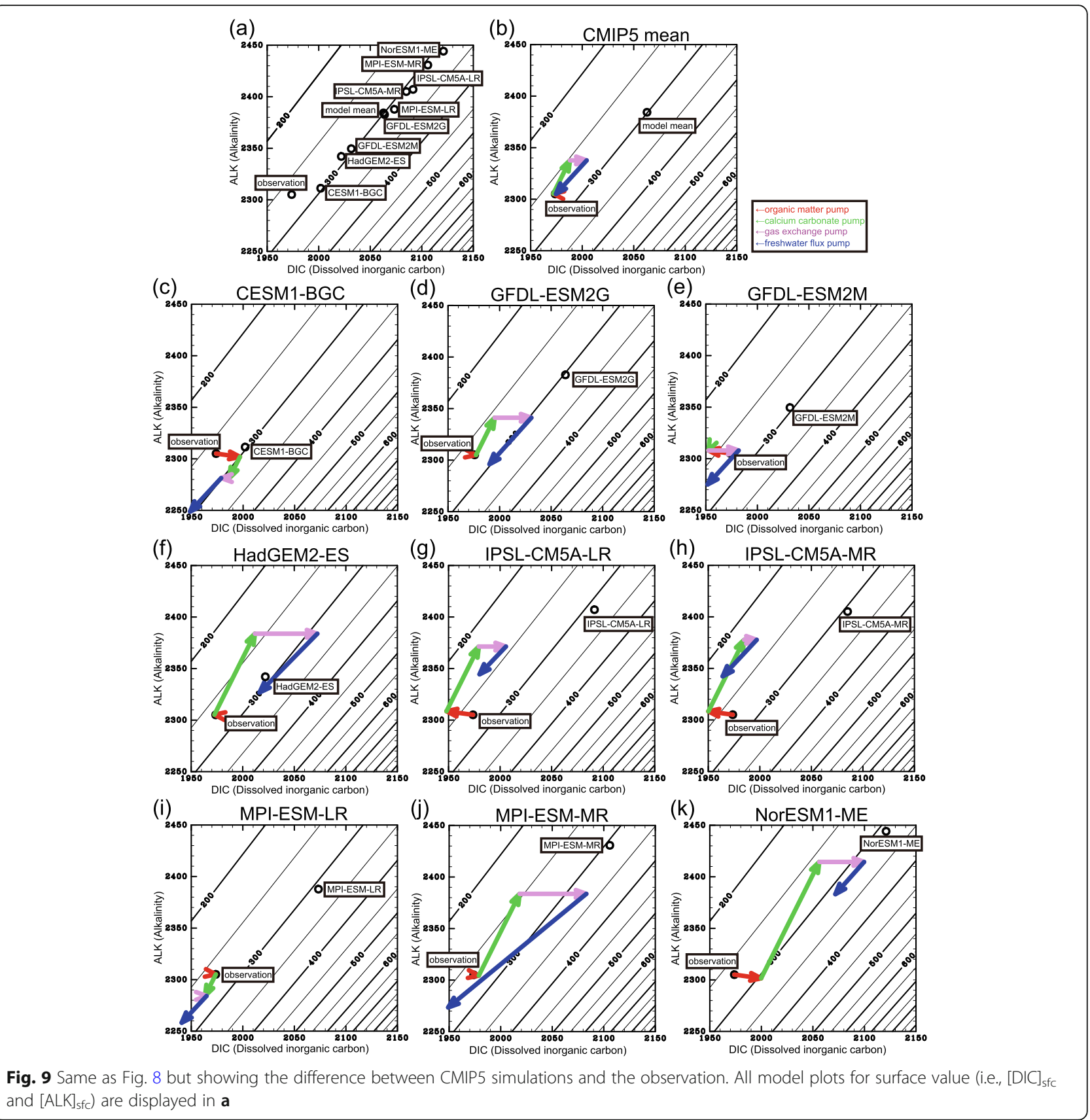

was decomposed into a globally averaged value and its deviation. Contrary to previous decomposition which emphasizes the deep-water enrichment of dissolved carbon from the surface value, our decomposition focuses on the surface depletion of dissolved carbon from its global average. It was shown that the deviation from the globally averaged value could be decomposed into four carbon pump components, which were defined such that their globally averaged values were always zero and the strength of each carbon pump was defined by the surface depletion of each carbon pump component.
The effects of the four carbon pumps on atmospheric $\mathrm{CO}_{2}$ concentration were summarized in a single figure (the vector diagram), in which each carbon pump component was represented by one vector and where its contribution to the ocean surface $\mathrm{pCO}_{2}$ could be measured from the difference in the contour values between the start and end of the vector.

By applying this method to the observational data, the contributions of the four carbon pump components to atmospheric $\mathrm{CO}_{2}$ concentration were evaluated. The same method of analysis was also applied to CMIP5 
ESM simulations. Although all the models reproduced the same level of atmospheric $\mathrm{CO}_{2}$ concentration as the observation, it was shown that the contributions from the four carbon pumps were not the same among the models. The individual strengths of the four ocean carbon pumps differed between the models, but they are all controlled such that their total effect on atmospheric $\mathrm{CO}_{2}$ concentration remains close to the observation as a result of adjustment by the gas exchange pump. The vector diagram was demonstrated as useful for both diagnosing how these four ocean carbon pumps operate and affect atmospheric $\mathrm{CO}_{2}$ concentration in each model and illustrating the differences among the models and their biases from the observation.

In summary, the vector diagram analysis introduced in this study was shown to be a useful tool for quantifying the individual contributions of ocean carbon pumps on atmospheric $\mathrm{CO}_{2}$ concentration. The method was also demonstrated as useful for evaluating the reproducibility of ocean carbon cycle models, and thus, it could serve as a simple method for evaluating and comparing the various model outputs amongst themselves and against the observation. Although the vector diagram analysis shown here was introduced as a tool for diagnosing the present-day ocean carbon pumps, this method could be widely applicable to various other problems. For example, the ocean carbon cycle is expected to continue to change in the future, and therefore, it is important to discuss the future changes in ocean carbon pumps and their roles in atmospheric $\mathrm{CO}_{2}$ concentration; applying the carbon pump decomposition and the vector diagram analysis to CMIP ESM future climate predictions will be an interesting approach. Extending the method to timevarying field, and for example, applying it for understanding the seasonal variation of the oceanic $\mathrm{pCO}_{2}$ (Gallego et al. 2018) might be also interesting. Discussing the changes in ocean carbon pumps in paleoclimate such as glacial climate by using the method proposed here is another interesting application.

\section{Abbreviations}

DIC: Dissolved inorganic carbon; ALK: Alkalinity; CMIP: Coupled Model Intercomparision Project; ESM: Earth System Model

\section{Acknowledgements}

Comments from two anonymous reviewers are helpful for improving the manuscript and greatly appreciated. The author acknowledges discussions with Drs. M. Shigemitsu, A. Yamamoto, and H. Kobayashi. The help from Y. Nakamura for handling CMIP5 data is also appreciated. The figures were prepared using the Dennou Library.

\section{Author's contributions}

AO proposed the topics and designed the study. The author read and approved the final manuscript.

\section{Funding}

The author is supported by MEXT KAKENHI grant number JP19H01963 and JP17H06323.

\section{Availability of data and materials}

DIC and ALK climatology of GLODAP dataset are publicly available from: https://www.nodc.noaa.gov/ocads/oceans/glodap/GlopDV.html. Phosphate, temperature, and salinity climatology of WOA dataset is publicly available from: https://www.nodc.noaa.gov/OC5/WOA01/pr_woa01.html. The CMIP5 data are publicly available from http://pcmdi9.Inl.gov/.

\section{Competing interests}

The authors declare that they have no competing interest.

Received: 19 December 2019 Accepted: 22 May 2020

Published online: 11 June 2020

\section{References}

Anderson LA, Sarmiento JL (1994) Redfield ratios of remineralization determined by nutrient data analysis. Glob Biogeochem Cycles 8:65-80 https://doi.org/10 1029/93GB03318

Baes CFJ (1982) Effects of ocean chemistry and biology on atmospheric carbon dioxide. Carbon dioxide Rev 1982 / Ed by William C Clark

Bentsen M, Bethke I, Debernard JB et al (2013) The Norwegian Earth System Model, NorESM1-M-part 1: description and basic evaluation of the physical climate. Geosci Model Dev 6:687-720 https://doi.org/10.5194/ gmd-6-687-2013

Bopp L, Monfray P, Aumont O et al (2001) Potential impact of climate change on marine export production. Glob Biogeochem Cycles 15:81-99 https://doi.org/ 10.1029/1999GB001256

Bopp L, Resplandy L, Orr JC et al (2013) Multiple stressors of ocean ecosystems in the 21st century: projections with CMIP5 models. Biogeosciences 10:62256245 https://doi.org/10.5194/bg-10-6225-2013

Broecker W, Peng T (1982) Tracers in the Sea

Cameron DR, Lenton TM, Ridgwell AJ et al (2005) A factorial analysis of the marine carbon cycle and ocean circulation controls on atmospheric CO2. Glob Biogeochem Cycles 19. https://doi.org/10.1029/2005GB002489

Chikamoto M, Abe-Ouchi A, Oka A (2012) Quantifying the ocean's role in glacial CO2 reductions. Clim Past 8. https://doi.org/10.5194/cp-8-545-2012

Collins WJ, Bellouin N, Doutriaux-Boucher M et al (2011) Development and evaluation of an Earth-System model - HadGEM2. Geosci Model Dev 4:10511075 https://doi.org/10.5194/gmd-4-1051-2011

Conkright M, Garcia H, O'Brien T et al (2002) World Ocean Atlas 2001. Sliver Sprint

Dufresne J-L, Foujols M-A, Denvil S et al (2013) Climate change projections using the IPSL-CM5 Earth System Model: from CMIP3 to CMIP5. Clim Dyn 40:21232165 https://doi.org/10.1007/s00382-012-1636-1

Dunne JP, John JG, Shevliakova E et al (2013) GFDL's ESM2 global coupled climate-carbon earth system models. Part Il: carbon system formulation and baseline simulation Characteristics. J Clim 26:2247-2267 https://doi.org/10. 1175/JCLI-D-12-00150.1

Flato GM (2011) Earth system models: an overview. Wiley Interdiscip Rev Clim Chang 2:783-800 https://doi.org/10.1002/wcc.148

Fu W, Randerson JT, Moore JK (2016) Climate change impacts on net primary production (NPP) and export production (EP) regulated by increasing stratification and phytoplankton community structure in the CMIP5 models. Biogeosciences 13:5151-5170 https://doi.org/10.5194/bg-13-5151-2016

Gallego MA, Timmermann A, Friedrich T, Zeebe RE (2018) Drivers of future seasonal cycle changes in oceanic pCO 2. Biogeosciences 15:5315-5327 https://doi.org/10.5194/bg-15-5315-2018

Giorgetta MA, Jungclaus J, Reick CH et al (2013) Climate and carbon cycle changes from 1850 to 2100 in MPI-ESM simulations for the Coupled Model Intercomparison Project phase 5. J Adv Model Earth Syst 5:572-597 https:// doi.org/10.1002/jame.20038

Gottschalk J, Battaglia G, Fischer H et al (2019) Mechanisms of millennial-scale atmospheric CO2 change in numerical model simulations. Quat Sci Rev 220: 30-74 https://doi.org/10.1016/J.QUASCIREV.2019.05.013

Ito T, Follows MJ (2005) Preformed phosphate, soft tissue pump and atmospheric CO $<$ SUB $>2</$ SUB $>$. J Mar Res 63:813-839 https://doi.org/10.1357/ 0022240054663231

Key RM, Kozyr A, Sabine CL et al (2004) A global ocean carbon climatology: results from Global Data Analysis Project (GLODAP). Glob Biogeochem Cycles 18. https://doi.org/10.1029/2004GB002247 
Khatiwala S, Schmittner A, Muglia J (2019) Air-sea disequilibrium enhances ocean carbon storage during glacial periods. Sci Adv 5:eaaw4981 https://doi.org/10. 1126/sciadv.aaw4981

Kobayashi H, Abe-Ouchi A, Oka A (2015) Role of Southern Ocean stratification in glacial atmospheric $\mathrm{CO} 2$ reduction evaluated by a three-dimensional ocean general circulation model. Paleoceanography 30:1202-1216 https://doi.org/ 10.1002/2015PA002786

Kobayashi $\mathrm{H}$, Oka A (2018) Response of atmospheric $p \mathrm{CO}_{2}$ to glacial changes in the Southern Ocean amplified by carbonate compensation. Paleoceanogr Paleoclimatology 33:1206-1229 https://doi.org/10.1029/2018PA003360

Kwon EY, Primeau F (2008) Optimization and sensitivity of a global biogeochemistry ocean model using combined in situ DIC, alkalinity, and phosphate data. J Geophys Res Ocean 113:1-23 https://doi.org/10.1029/ 2007JC004520

Kwon EY, Primeau F, Sarmiento JL (2009) The impact of remineralization depth on the air-sea carbon balance. Nat Geosci 2:630-635 https://doi.org/10.1038/ ngeo612

Kwon EY, Sigman DM, Hain MP et al (2012) North Atlantic ventilation of "southern-sourced" deep water in the glacial ocean. Paleoceanography 27 https://doi.org/10.1029/2011 pa002211

Lindsay K, Bonan GB, Doney SC et al (2014) Preindustrial-control and twentiethcentury carbon cycle experiments with the Earth System Model CESM1(BGC). J Clim 27:8981-9005 https://doi.org/10.1175/JCLI-D-12-00565.1

Marinov I, Follows M, Gnanadesikan A et al (2008) How does ocean biology affect atmospheric pCO2? Theory and models. J Geophys Res 113:C07032 https://doi.org/10.1029/2007JC004598

Mecking JV, Drijfhout SS, Jackson LC, Andrews MB (2017) The effect of model bias on Atlantic freshwater transport and implications for AMOC bi-stability Tellus SERIES A DYANAMIC METEOROLOGY AND OCEANOGRAPHY PUBLISHED BY THE INTERNATIONAL METEOROLOGICAL INSTITUTE IN STOCKHOLM The effect of model bias on Atlanti. Dyn Meteorol Oceanogr 69 https://doi.org/10.1080/16000870.2017.1299910

Millero FJ (1995) Thermodynamics of the carbon dioxide system in the oceans [ $\mathrm{H}+\mathrm{I}$ [ B (OW ; I [ B (OHhl.) Science (59:661-677. https://doi.org/10.1016/ 0016-7037(94)00354-O

Nakamura Y, Oka A (2019) CMIP5 model analysis of future changes in ocean net primary production focusing on differences among individual oceans and models. J Oceanogr 75:441-462 https://doi.org/10.1007/s10872-01900513-w

Oka A, Abe-Ouchi A, Chikamoto MO, Ide T (2011a) Mechanisms controlling export production at the LGM: effects of changes in oceanic physical fields and atmospheric dust deposition. Glob Biogeochem Cycles 25 https://doi. org/10.1029/2009GB003628

Oka A, Kato S, Hasumi H (2008) Evaluating effect of ballast mineral on deepocean nutrient concentration by using an ocean general circulation model. Glob Biogeochem Cycles 22. https://doi.org/10.1029/2007GB003067

Oka A, Tajika E, Abe-Ouchi A, Kubota K (2011b) Role of the ocean in controlling atmospheric CO2concentration in the course of global glaciations. Clim Dyn 37:1755-1770 https://doi.org/10.1007/s00382-010-0959-z

Phillips TJ, Gleckler PJ (2006) Evaluation of continental precipitation in 20th century climate simulations: the utility of multimodel statistics. Water Resour Res 42. https://doi.org/10.1029/2005WR004313

Sarmiento JL, Gruber N (2002) Sinks for anthropogenic carbon. Phys Today 55: 30-36 https://doi.org/10.1063/1.1510279

Sarmiento JL, Gruber N (2006) Ocean biogeochemical dynamics

Sarmiento JL, Hughes TMC, Stouffer RJ, Manabe S (1998) Simulated response of the ocean carbon cycle to anthropogenic climate warming. Nature 393:245249 https://doi.org/10.1038/30455

Shigemitsu M, Yamamoto A, Oka A, Yamanaka Y (2017) One possible uncertainty in CMIP5 projections of low-oxygen water volume in the Eastern Tropical Pacific. Glob Biogeochem Cycles 31. https://doi.org/10. 1002/2016GB005447

Sigman DM, Boyle EA (2000) Glacial/interglacial variations in atmospheric carbon dioxide. Nature 407:859-869 https://doi.org/10.1038/35038000

Sigman DM, Hain MP, Haug GH (2010) The polar ocean and glacial cycles in atmospheric CO2concentration. Nature 466:47-55 https://doi.org/10.1038/ nature09149

Solomon S, Qin D, Manning M, et al (2007) Climate change: the physical science

Taylor KE, Stouffer RJ, Meehl GA (2012) An overview of CMIP5 and the experiment design. Bull Am Meteorol Soc 93:485-498 https://doi.org/10. 1175/BAMS-D-11-00094.1
Volk T, Hoffert M (1985) Ocean carbon pumps: analysis of relative strengths and efficiencies in ocean-driven atmospheric $\mathrm{CO} 2$ changes. In: The Carbon Cycle and Atmospheric CO2, pp 99-110

Yamamoto A, Abe-Ouchi A, Ohgaito R et al (2019) Glacial CO2 decrease and deep-water deoxygenation by iron fertilization from glaciogenic dust. Clim Past 15:981-996 https://doi.org/10.5194/cp-15-981-2019

Yamamoto A, Abe-Ouchi A, Yamanaka Y (2018) Long-term response of oceanic carbon uptake to global warming via physical and biological pumps. Biogeosciences 15:4163-4180 https://doi.org/10.5194/bg-15-4163-2018

Yamanaka Y, Tajika E (1996) The role of the vertical fluxes of particulate organic matter and calcite in the oceanic carbon cycle: studies using an ocean biogeochemical general circulation model. Glob Biogeochem Cycles 10:361382 https://doi.org/10.1029/96GB00634

Yoshikawa C, Kawamiya M, Kato T et al (2008) Geographical distribution of the feedback between future climate change and the carbon cycle. J Geophys Res 113:G03002 https://doi.org/10.1029/2007JG000570

Zickfeld K, Eby M, Weaver AJ (2008) Carbon-cycle feedbacks of changes in the Atlantic meridional overturning circulation under future atmospheric $\mathrm{CO}_{2}$ Glob Biogeochem Cycles 22 https://doi.org/10.1029/2007GB003118

\section{Publisher's Note}

Springer Nature remains neutral with regard to jurisdictional claims in published maps and institutional affiliations.

\section{Submit your manuscript to a SpringerOpen ${ }^{\circ}$ journal and benefit from:}

- Convenient online submission

- Rigorous peer review

- Open access: articles freely available online

High visibility within the field

- Retaining the copyright to your article

Submit your next manuscript at $>$ springeropen.com 